\title{
توطين سلاسل التوريد في مصر: السياسات والبرامج بالتطبيق على سلسلة توريد الألبان ومنتجاتها
}

\section{د. علي زين العابدين}

\section{ملخص}

اقترحت هذه الدر اسة استر اتيجية لتوطين سلاسل توريد الألبان تتكون من برنامجين، وثمانية مشرو عات تستهدف: (1) الوصول بإنتاج الألبان السنوي من الماثشية التقليدية إلى 7.5 مليون طن بعد خمس سنوات، و إلى 11 مليون طن بعد عشر سنوات. (2)

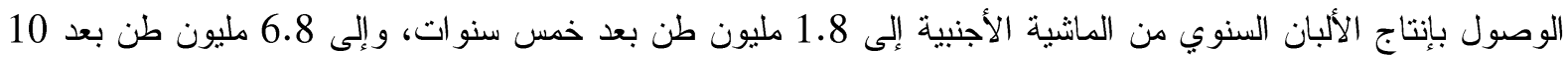

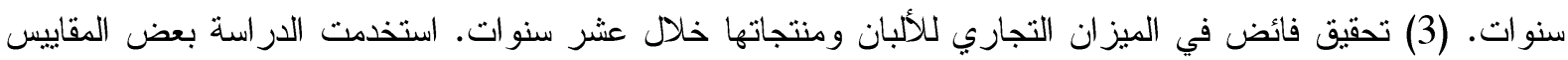
الكمية مثل تحليل الاتجاه العام للسلاسل الزمنية، واختبار ات الفروق بين المتوسطات (اختبار ت). ولقياس مدى تتافسية الألبان

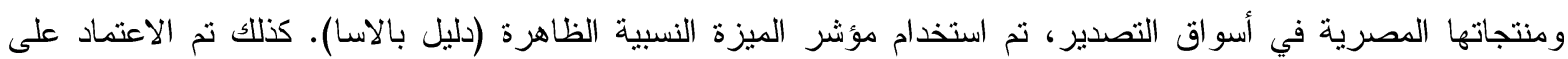
حسابات خريطة التجارة، و الخاصة بكلٍ من تركيز دول التوريد، ومتوسط المسافة مع دول التوريد. وقد أوصت الدر اسة بعدد من السياسات، هي: (1) تخفيض تكاليف استخدامات الطاقة. (2) خفض منوسط عدد الأميال التي

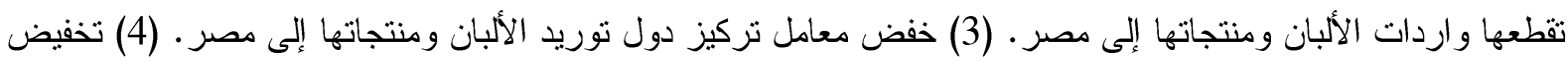

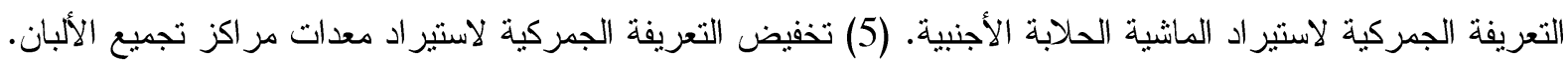

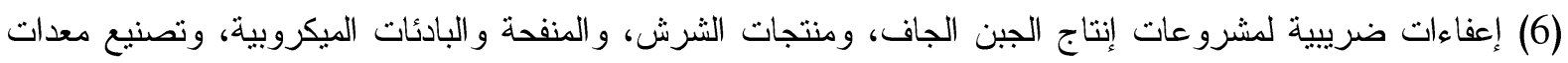

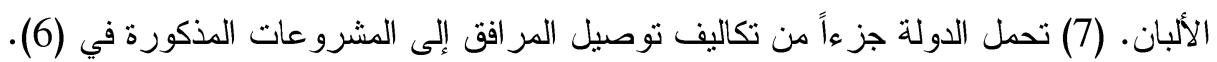

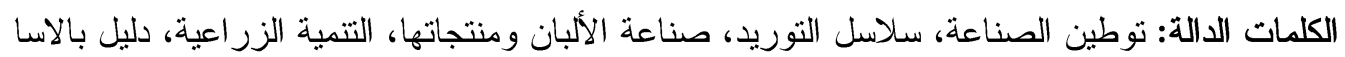

\section{Abstract}

\section{Localization of Supply Chains in Egypt: Policies and Programs with Application on Dairy Products Value Chain to the Supply Chain of Milk and Dairy Products}

This study proposed a strategy for the localization of dairy supply chains targeting contains two programs, and eight projects, aim to: (1) The annual milk production of traditional livestock reaches 7.5 million tons after decade, and to 11 million tons after ten years. (2) The annual milk production of foreign livestock reaches 1.8 million tons after five years, and to 6.8 million tons after 10 years. (3) To achieve a surplus in the trade balance of dairy products within ten years. The study used some quantitative measures such as trend analysis for time series, and (T-test). In order to measure the competitiveness of Egyptian dairy products in the export market, the revealed comparative advantage (RCA) index (Balassa Index) was used. The trade map calculations were also relied on, for the concentration of the countries that supply milk and its products into Egypt, and the average distance with these countries.

The study also recommended a number of policies, namely: (1) Reducing the costs of energy use. (2) Reducing the average number of miles traveled by imports of milk and dairy products into Egypt. (3) Reducing the concentration factor of countries supplying milk and dairy products to Egypt. (4) Reducing tariffs for importing foreign milking livestock. (5) Reducing customs tariffs for importing dairy collection center equipment. (6) Tax exemptions for enterprises producing dry cheese, whey products, microbial rennet and starters, and manufacturing of dairy equipment. (7) The state bears part of the costs of connecting the facilities to the projects mentioned in (6)

Keywords: Industry localization, Supply chain, Milk and dairy products, Agricultural development, Balassa index 
وفقاً لمعجم كامبريدج يعرف التوطين Localization بأنه "عملية تنظيم شركة أو صناعة بحيث تتم

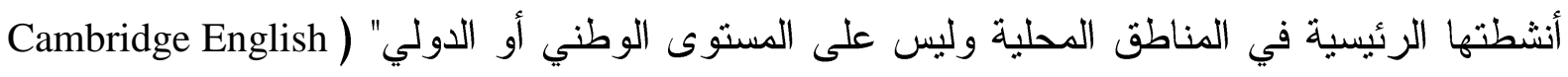
Dictionary, 2020 ). ومن المنظور النسويقي، يعرف التوطين بأنه: "عملية جعل منتج أو خدمة أكثر ملاءمة لبلد أو منطقة معينة". و وعرفت إحدى الدر اسات التوطين بأنه الموقع المادي للمر افق و المؤسسات. وبشكل أكثر تحديدا، يتعلق التوطين بموضع الموارد الإنتاجية (المسماة "التصنيع")، وموقع قاعدة الموردين (المسماة "المشتريات")، وموضع المستودعات و النقل (المسماة "اللوجسنيات")، وكذلك موضع مر اكز البحوث و النظوير ومدى التنسيق فيما بينها (Rickard \& Martin, 2020). Weber, ) وقد بدأ فكر التوطين مع ظهور نظرية موقع الصناعات للاقتصادي الألماني ألفريد ويبر لهرير

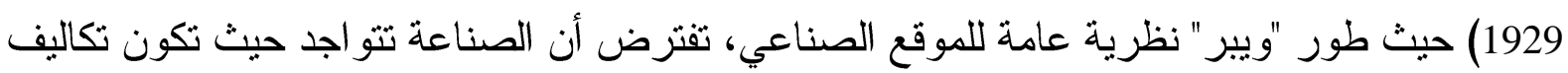
نقل المواد الخام والمنتج النهائي عند حدها الأدنى. وخص بالذكر حالتين خاصتين من النظرية. في إحداها يكون وزن المنتج النهائي أقل من وزن المادة الخام المستخدمة في صنع المنتج. وهذه هي حالة فقدان الوزن، وعندها من الأفضل أن يكون موقع الصناعة بالقرب من المادة الخام. وفي الحالة الثانية يكون المنتج أثقل من المو اد الخام، وعادةً ما تكون هذه حالة بعض المو اد الخام الموجودة في كل مكان مثل الماء الذي يتم دمجه في المنتج، و هذا ما بسمى حالة زيادة الوزن. ويفضل في الحالة الأخيرة أن يكون موقع الصناعة أقرب إلى السوق. ومن المهم أن يكون النوطين تدريجياً، بحيث يتم جذب المزيد من الاستثمار ات الأجنبية للشركات العالمية في مختلف الصناعات المُراد نوطينها، مثل صناعة المركبات، ووسائل النقل الكهربائية، والإلكترونيات على سبيل المثال في حالة مصر . ثم يلي ذلك العمل على تطوير سلاسل التوريد المحلية المغذية لتلك الصناعات حتى بسنطيع المكون المحلى أن بشكل السواد الأعظم من تلك المنتجات التي ينم إنتاجها داخل الدولة. وبعد ذلك، ستككون الفرص أكثر ملاعمة أمام ظهور منتجات محلية خالصة عالية التقنية. و على الرغم من ذلك، لا يعنى "توطين الصناعات" منع الاستير اد أو رفع تكلفته لأن في كل الصناعات

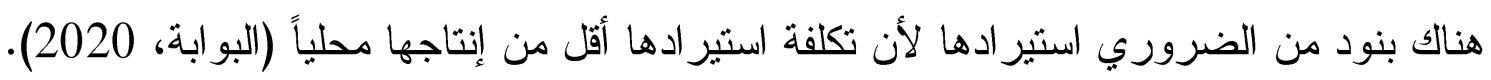
وتتص رسالة وزارة التجارة والصناعة في مصر على: "تقل وتوطين التكنولوجيا وتنبي المبادرات الابتكارية اللازمة لنطوير الصناعة المصرية وتقديم الدعم الفني ورفع الكفاءات الفنية وزيادة القيمة المضافة للمنتجات المحلية وبناء شبكة من العلاقات والقدرات الدولية" (وزارة التجارة والصناعة، 
2020). كما تهنم رؤية مصر 2030 بتعميق الككون المحلى في السلع الصناعية و الارتقاء في سلاسل القيمة، العمل على تحقيق الترابط و التكامل بين المناطق الصناعية والدناطق الحرة وسلاسل القيمة المحلية والإقليمية و العالمية (وزارة التخطيط و التتمية الاقتصادية، 2016). وقد أبدت رئاسة الجمهورية اهتماما بملف توطين الصناعة، والتوسع في الصناعات التي تحتاجها الأسواق المحلية، وتخفيض الاستير اد، و العمل على توطين التكنولوجيا (مباشر مصر، 2020). ومن مظاهر هذا الاهتمام الشروع في إطلاق الاستراتيجية القومية لتوطين صناعة المركبات والصناعات المغذية لها في مصر (الهيئة القومية للاستعلامات، 2020) مع التزكيز على توطين وسائل النقل الكهربائية وعربات القطار (الثروق، 2020). وكذلك توطين صناعة البلازما اللازمة لاستخر اج المشتقات الهامة و الحيوية منها لاستخداماتها الطبية المتعددة (اليوم السابع، 2020-1).

و ألقت أزمة كوفيد-19 بانعكاساتها على كفاءة سلاسل التوريد عامة، و على سلاسل نوريد المستلزمات الطبية والغذاء على وجه الخصوص. وقد أصبح لتوطين الغذاء كحركة معاكسة للعولمة دور كبير في تعزيز استدامة النظم الغذائية في الاقتصادات المتقدمة. كما أن نوطين الغذاء من شأنه إعادة تشكيل الروابط بين إنتاج الغذاءو استهلاكه، ومن ثم تقليل الأميال التي يقطعها الغذاء للوصول إلى المستهلكين. ولتوطين الغذاء فو ائد عديدة منها: تعزيز التتمية الاقتصادية المحلية، وتوفير المزيد من فرص العمل في المناطق البعيدة عن العو اصم، وزيادة إتاحة الغذاء في تلك المناطق، وتحسين جودة وسلامة الغذاء أيضاً من خلال قرب المنتج من الأسواق، ومن ثم فستقل الحاجة لوسائل حفظ الغذاء خاصةً المثير منها للجدل .(Zhong, 2020) وفي أغسطس من العام الحالي، 2020، وجه الرئيس القيادة السياسية بدعم المشروع القومي لإنشاء وتطوير مر اكز تجميع الألبان على مسنوى الجمهورية، بما يساهم في تكوين منظومة متكاملة تعظم من إنتاج الألبان كماً ونوعاً وتتيح إقامة الصناعات الغذائية ذات الصلة (اليوم السابع، 2020-2). ويعد قطاع الألبان ومنتجاتها من أهم قطاعات الاقتصاد الزراعي المصري. حيث ساهم هذا القطاع بمفرده بنحو 20.76\% من قيمة الإنتاج الحيواني، وحوالي 11.98\% من صافي قيمة الإنتاج الزراعي المصري في العام المالي 2018/2017 (الجهاز المركزي للتعبئة العامة والإحصاء، 2020). وعلى

\section{${ }^{1}$ Food Miles.}


الرغم من هذا التميز ، إلا أن العجز في الميزان التجاري للألبان ومنتجاتها قد بلغ نحو 336 مليون دولار عام 2019.

لذا، تستهدف هذه الدر اسة بحث آليات وممكنات توطين سلاسل التوريد في مصر بالنطبيق على سلسلة توريد الألبان ومنتجاتها كدر اسة حالة. حيث تم إجراء تحليل تفصيلي لسلسلة توريد الألبان ومنتجاتها في مصر، و الوقوف على أهم التحديات التي تسببت في زيادة الواردات عن الصادرات، وبحث ما هي السياسات والبرامج التي يمكن اقتراحها لمساعدة صانعي القرار للاستفادة من قطاع تثير عديد من الدراسات (سليمان وجابر ، 2008) أن لمصر فيه ميزة نسبية كأحد المصادر الرئيسية للبروتين الحيو اني، ودعامة من دعائم الأمن الغذائي المصري. 1.1. المنهجية ومصادر البيانات:

استخدمت الدراسة بعض المقاييس الكمية مثل تحليل الاتجاه العام للسلاسل الزمنية، واختبارات الفروق بين المتوســـات (اختبار ت) لرصـــــ النطور في الكميات المنتجة من الألبان ومنتجاتها، وكذلك

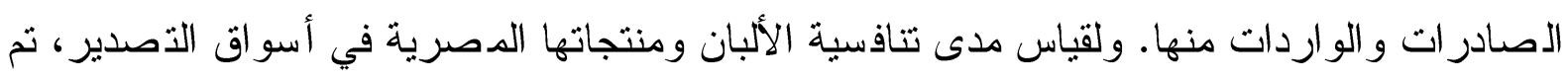

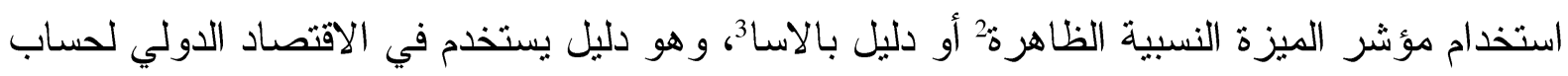
الميزة الذ سبية المقارنة لدولة ما في أحد قطاعات المنتجات أو الخدمات من خلال تدفقاتها التجارية في هذا القطاع. حيث يتم حساب الميزة النسبية الظاهرة كما يلي:

$$
R C A_{p c t}=\frac{x_{p c t} / X_{c t}}{x_{w p t} / X_{w t}}
$$

حيث:

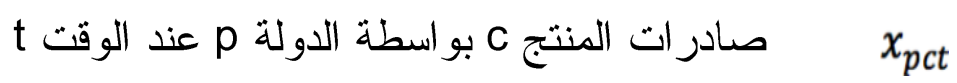

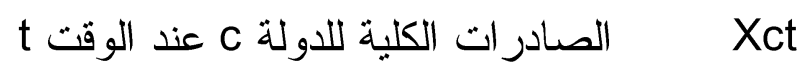

t الصادرات الكلية للعالم من المنتج C عند الوقت

t Xwt

\section{${ }^{2}$ Revealed Comparative Advantage (RCA).}

${ }^{3}$ Balassa Index. 
حيث تصبح الميزة النسبية ظاهرة لدولة ما في منتج معين إذا كانت قيمة RCA أكبر من 1. و إذا كانت

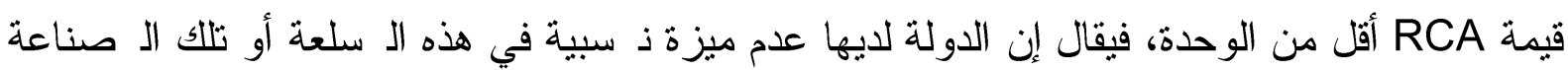
.(Balassa, 1965) كذلك تم الاعتماد على حســابات خريطة التجارة Trade Map المنعلقة بالترتيب العالمي للدول الدصدرة و الدستوردة، ومشاركة الدول في صادر ات وواردات العالم من الألبان ومنتجاتها، و النمو في كميات وقيم الصــادر ات و الو اردات، وحســابات الموازين التجارية للمجموعات المختلفة من منتجات الألبان.

كما تم الاعتماد على ح سابات خريطة التجارة Trade Map أي ضاً، و الخا صة بكلٍ من تركيز دول

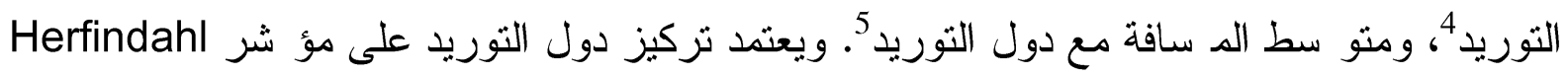
الذى يتم حسابه من خلال تربيع نصيب كل دولة في السوق المختارة، ثم يتم جمع الأرقام الناتجة.

$$
H=\sum_{i=1}^{N} s_{i}^{2}
$$

حيث si هي حصة البلد أ في السوق، وN هي عدد البلدان. يتر اوح مؤشر هرفندال من N/ إلى واحد. كذلك فإن منوسط المسافة بين البلدان الموردة أو المستوردة لمنتج محدد نم حسابه - وفقاً لخريطة التجارة-كمتوسط مرجح للمسافة بين الدولة المختارة وجميع البلدان الثريكة مرجحًا بقيم التجارة. وقد اعتمدت الدراسة على البيانات الثانوية الني تتشرها الوزارات و الهيئات الحكومية، و المنظمات الإقليمية و الدولية ذات الصلة بموضوع الدراسة.

\footnotetext{
${ }^{4}$ Concentration of supplying countries.
}

${ }^{5}$ Average distance of supplying countries 
2. سلسة توريد الألبان ومنتجاتها في مصر

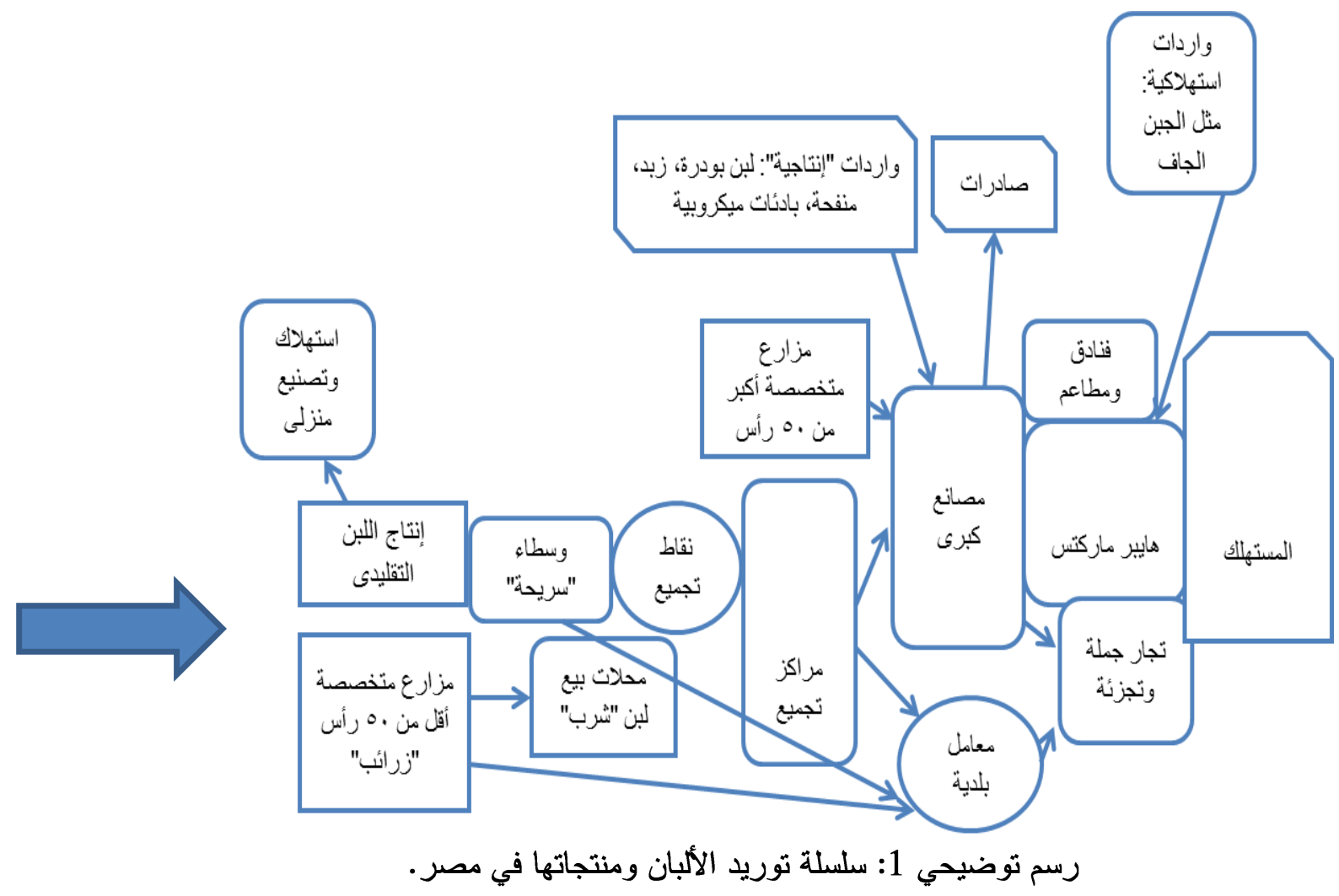

المصدر : الباحث

\section{1. توصيف سلسلة توريد الألبان ومنتجاتها}

يتتاول هذا الجزء، تحليل سلسلة توريد الألبان ومنتجاتها من حيث: التوزيع الجغر افي لإنتاج الألبان، أنماط إنتاج الألبان، أنماط استهلاك الألبان، التوزيع الجغر افي لتصنيع الألبان في مصر، نطور أعداد الماشية وكميات الألبان المنتجة، وتطور الصادرات و الو اردات و المتاح للاستهلاكك من الألبان ومنتجاتها، وتطور الواردات من الألبان المجففة.

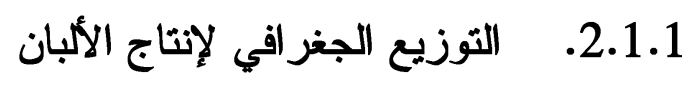

تقدر أعداد المانية الحلابة الرئيسية (الأبقار و الجاموس) في مصر في عام 2018 بحو الي 7.8 مليون رأس، منها 4.4 مليون رأس من الأبقار، ونحو 3.4 مليون رأس من الجاموس، تتتج نحو 5.1 مليون طن من الألبان، نساهم الأبقار بنحو 2.9 مليون طن منها، بينما يساهم الجاموس في إنتاج 2.2 مليون

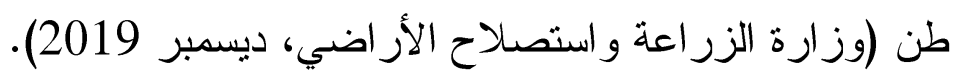


ويتركز إنتاج الألبان في مصر من الأبقار والجاموس في الوجه البحري، حيث تنتج محافظات الوجه

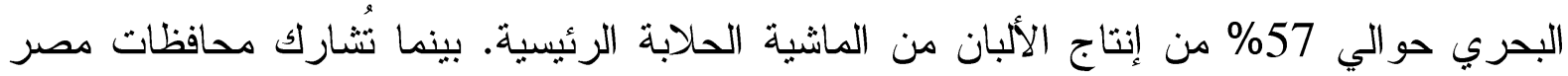
الوسطى ومصر العليا مجتمعة في إنتاج 36\% من الألبان، و لا تساهم محافظات خارج الو ادي إلا بنسبة ضئيلة لا تتجاوز 7\% من الإنتاج. وتعد محافظة البحيرة الأولى على مستوى الجمهورية في إنتاج ألبان الأبقار و الجاموس، وتتتج بمفردها 15\% من الإنتاج. وتساهم تسع محافظات أخرى بالإضافة إلى البحيرة في إنتاج ما يقرب من 72\% من إنتاج الألبان من الأبقار و الجاموس في مصر، منها أربع محافظات في الوجه البحري، هي: المنوفية و الثرقية و الغربية و الدقهلية، وثلاث محافظات في صعيد مصر، هي: الفيوم وبنى سويف و المنيا، بينما لم تثواجد سوى النوبارية من خارج الو ادي في قائمة التميز لإنتاج الألبان من الماشية الحلابة الرئيسية (وزارة الزراعة واستصلاح الأراضي، ديسمبر 2019). 2.1.2 أنماط إنتاج الألبان

ويعتمد إنتاج الألبان في مصر بصفة أساسية على القطاع التقليدي الذي ينتج الألبان في المنازل الريفية في الوجهين البحري و القبلي (96.7\% من الماشية الحلابة الرئيسية). أما مزارع إنتاج الألبان المتخصصة، فقد بلغ عددها عام 2018 نحو 6173 مزرعة، تتتج حو الي 0.87 مليون طن تمثل نحو

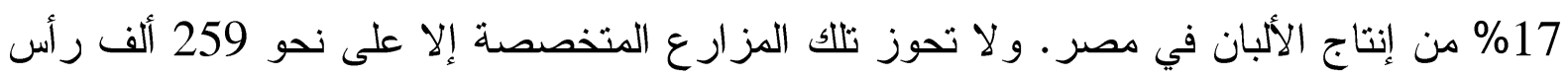
من الأبقار و الجاموس، تمثل فقط 3.3\% من الماشية الحلابة الرئيسية. ولربما دل ذلك على الارتفاع النسبي في إنتاجية المانثية الحلابة في المز ارع المتخصصة مقارنةً بالقطاع التقليدي. ويبلغ متوسط إنتاج الرأس من الأبقار الخليطة، والجاموس المصري، والأبقار البلدية في المزارع المتخصصة نحو 2، 1.7، 1 طن سنوياً على التزتيب، بينما تتميز رأس الماشية من الأبقار الأجنبية بإنتاجية مرتفعة نسبياً تبلغ نحو 6 طن/سنة في المنوسط (وزارة الزراعة واستصلاح الأراضي، ديسمبر 2019). وتمتاز المزارع المتخصصة بتوفير العلائق المتوازنة -نسبياً-، والتي تعتمد على الأعلاف الجافة غالباً جنباً إلى جنب مع العلائق الخضر اء في حال توفر الأخيرة--، في حين يعاني القطاع التقليدي من التتاقص المستمر في المساحة المزروعة من الأعلاف الخضراء التي بلغت نحو 761 ألف هكتار عام 2016 مقارنة بما يقرب من 1140 ألف هكتار عام 2007 (منظمة الأمم المتحدة للأغذية و الزر اعة، 2020). وتقع 76\% من مزارع الألبان المتخصصة في الوجه البحري ومصر الوسطى، بينما تقع النسبة الباقية خارج الوادي وفي مصر العليا. وتمثل مزارع الألبان التي تحوز على 10 إلى أقل من 25 رأس ما لها

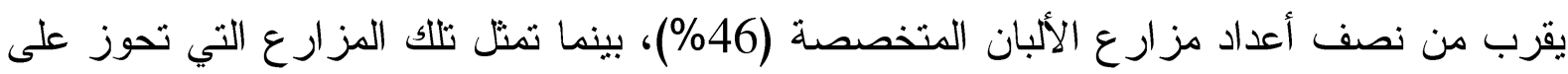


عدد رؤوس من 25 إلى أقل من 50 رأس نحو 29\%، أما المزارع التي تحوز على 50 رأس فأكثر فتمثل فقط 25\% من مزارع إنتاج الألبان المتخصصة في مصر. كما تمنل الأبقار الأجنبية ما يقرب من ثلث أعداد الرؤوس بتلك المزارع (32.1\%)، تليها الأبقار الخليطة والجاموس بنسب منساوية تبلغ 26.7\% لكل منهما، بينما تمثل الأبقار البلدية الخالصة حوالي 14.5\% من الماشية في مزارع إنتاج الألبان المتخصصة (وزارة الزر اعة واستصلاح الأراضي، ديسمبر 2019). وتقع حوالي 33\% من المزار ع المتخصصة في إنتاج الألبان في النوبارية، و الإسكندرية، و الفيوم. بينما تقع أكثر من 40\% من تلك المزارع في سبع محافظات أخرى، هي: الثرقية، الغربية، السويس، الجيزة، الأقصر، القليوبية، الدقهلية. 2.1.3

و على مستوى الاستهلاك، يُقدر استهلاك الألبان من قبل الوحدات المعيشية المنتجة له في القطاع التقليدي بنحو 40\% إما في صورة ألبان سائلة أو مصنعة تصنيعاً منزلياً، ويتضمن ذلك أيضاً رضاعة العجول الصغيرة. في حين يتوجه للتصنيع ما يقرب من 60\% من إنتاج الألبان فقط (عبد الجليل، 2020).

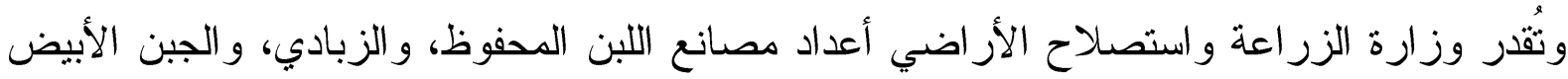
في مصر عام 2018 بنحو 26، 73، 1163 مصنعاً على التزتيب (وزارة الزراعة واستصلاح الأراضي، نوفمبر 2020). بينما تُقدر غرفة الصناعات الغذائية باتحاد الصناعات المصرية إجمالي أعداد مصانع الألبان بنحو 300 مصنعاً كرسمياًَ، وحو الي 5000 معمل لإنتاج الألبان صغير السعة (عبد الجليل، 2020). ويمثل إنتاج الجبن الركيزة الأساسية لصناعة الألبان في مصر ، حيث تستقبل مصانع إنتاج الجبن الأبيض، و اللبن الجفف، والجبن الجاف حوالي 750، 650، 80 ألف طن من اللبن الخام سنوياً (عبد الجليل،

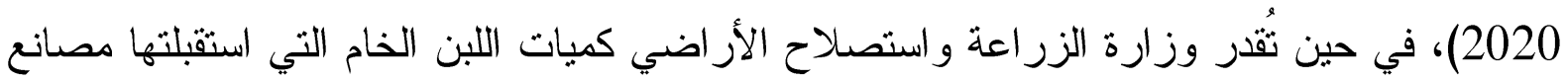
الجبن الأبيض عام 2018 بنحو 408 ألف طن، أنتجت 111.7 ألف طن من الجبن الأبيض. كما قدرت وزارة الزراعة واسنصلاح الأراضي أيضاً كميات الألبان الخام التي تم توريدها إلى مصانع اللبن المحفوظ، والزبادي بنحو 130، 23 ألف طن على الترتيب في ذات العام (وزارة الزراعة واستصلاح الأر اضي، نوفمبر 2020). 
2.1.4 التوزيع الجغر افي لتصنيع الألبان في مصر

يتضح من الثكل التوضيحي رقم (2) أن ما يقرب من 50\% من إنتاج الجبن ينم تصنيعه في ثلاث محافظات فقط، هي: الدقهلية، الإسكندرية، دمياط. وربما يرجع استيطان مصانع الجبن الأبيض لمحافظتي الإسكندرية ودمياط على الرغم من ندرة المادة الخام الرئيسية -اللبن الخام-، إلى أنهما

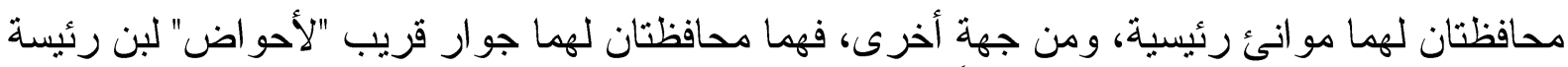
تتمثل في محافظتي البحيرة، والدقلية على الترتيب. والجدير بالذكر أن محافظتا الإسكندرية ودمياط يتميز اكذلك بوجود منطقتين صناعيتين يعمل بهما مصانع ألبان كبرى، هما: برج العرب، ودمياط

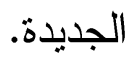

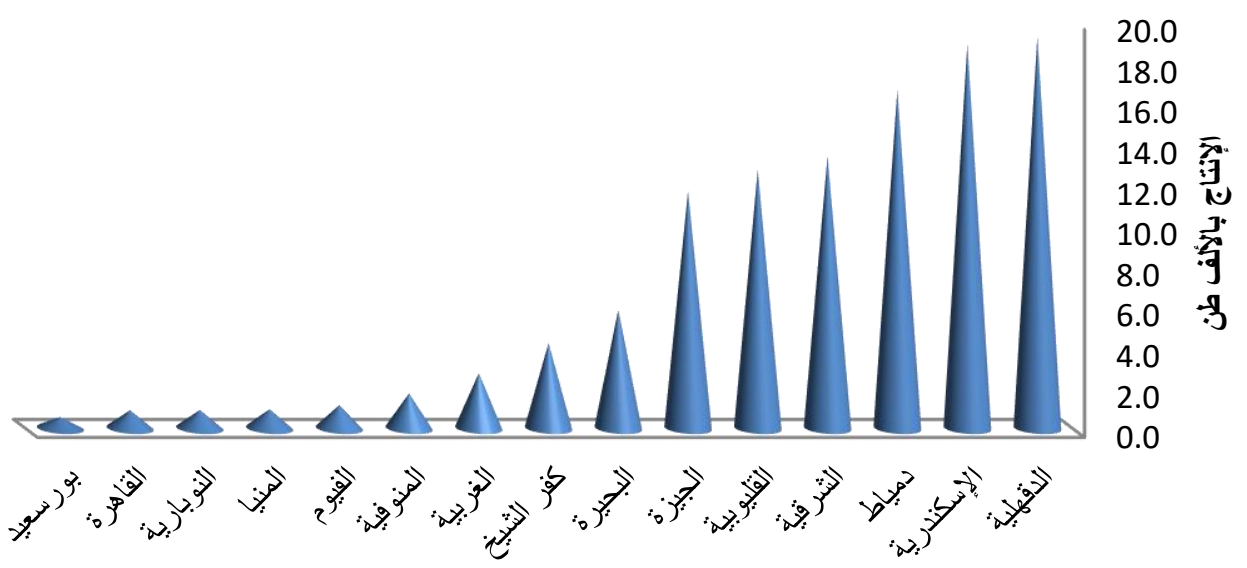

رسم توضيحي 2: محافظات التيز في إنتاج الجين الأبيض عام 2018. المصدر: وزارة الزراعة واستصلاح الأراضي، قطاع الشئون الاقتصادية، إحصاءات الثروة الحيوانية عام 2018، إصدار نوفمبر 2019.

كما يتبين من ذات الثكل أن أكثر من ثلث إنتاج الجبن الأبيض (33.8\%) ينم إنتاجه في ثلاث محافظات أخرى، وهي: الثرقية، و القليوبية، و الجيزة. و الثلاث محافظات السابقة يقع بها مناطق صناعية كبرى أيضاً، هي: العاشر من رمضان، العبور، السادس من أكتوبر . كما أن الثرقية تُعد من محافظات التمبز

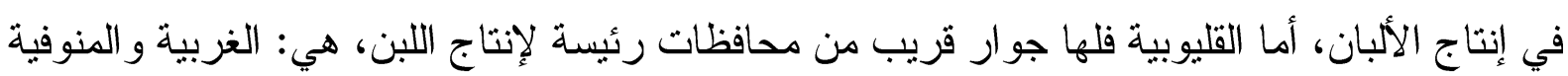

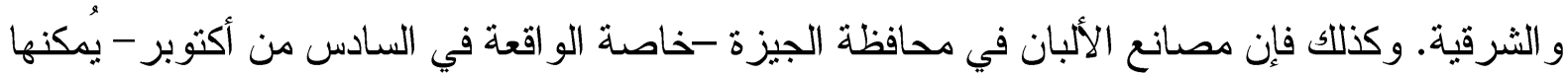
استقبال الألبان من محافظتي جو ار مُنتجتان للألبان هما: الفيوم وبنى سويف. وجميع المحافظات الثلاثوبالأحرى المناطق الصناعية الو اقعة بها - قريبة من أسواق المستهلكين، وتتو افر لها العمالة ذات الأجور 
المعتلة الوافدة من المحافظات المجاورة. وربما كانت تلك العوامل جميعها سبياً في نوطين صناعة الألبان ومنتجاتها داخل زمام تلك المحافظات.

\subsection{5 تطور أعداد الماشية وكميات الألبان المنتجة}

يتبين من الجدول رقم (1) بالملدق أن متوسط أعداد الماشية من الأبقار و الجاموس خلال الفترة من 2007 حتى 2016 يكاد تكون ثابتاً. حيث قدر متوسط أعدادها بحو الي 8.8 مليون رأس، بحد أدنى 8.4 مليوناً في عام 2009، وحد أقصى 9.2 مليون في عام 2008. و المعلوم أن مانشية الألبان التقليدية في مصر ليست على قدر عال من التخصص سواء في إنتاج اللحم أو إنتاج الألبان، فتعد معظم الثروة الحيو انية المصرية ثنائية الغرضٍٍ. لذا، ففي حال انحسار الطلب على إنتاج الألبان في أحد السنوات، يميل المز ارعون الذين تقع في ملكيتهم معظم الثروة الحيو انية في مصر إلى ذبح الماشية، و الاستفادة من عو ائد بيع لحومها. وينتج عن ذلك انخفاض كمية الألبان المنتجة في العام التالي، ومن ثم ارتفاع أسعار ها، وعندها يقبل المز ارعون على شر اء الماشية الحلابة والاحتفاظ بها مرة أخرى، ومن ثم يحدث زيادة في معروض اللبن في العام الثالي، فينخفض سعره، ويزيد معدلات الذبح مرة أخرى، وتستمر هذه الدروة دون توقف، وربما كان ذلك سبباً في ثبات أعداد الماشية خلال السنوات الأخبرة. وربما دل على ذللك، هُه عدم ثبوت المعنوية الإحصائية للفروق بين متوسط أعداد الأبقار والجاموس في الفترتين (2007-

2011)، (2012-2016)، كما هو موضح بالجدول رقم (1). جدول 1: مقارنة تطور أعداد رؤوس الأبقار و الجاموس خلال الفترتين (2007-2011)، (2012-2016)

\begin{tabular}{|c|c|c|c|c|c|c|}
\hline \multirow{2}{*}{ المذبوحات } & \multirow{2}{*}{ والجأبقالي } & \multirow[b]{2}{*}{ 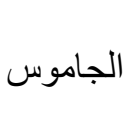 } & \multicolumn{3}{|c|}{ الأبقار } & \multirow[b]{2}{*}{ المتغير } \\
\hline & & & ال الإجمالي & الأجنبي & المحلية & \\
\hline 2700.6 & 8706.8 & 3954 & 4752.8 & 148.6 & 4604.2 & متوسط الفترة (2007-2011) \\
\hline 2550.8 & 8804.6 & 3935 & 4869.6 & 179.8 & 4689.8 & متوسط الفترة (2012-2016) \\
\hline 2.324 & -0.584 & 0.248 & -1.168 & -1.265 & -0.937 & قيمة ت الإحصائية \\
\hline 0.0404 & 0.295 & 0.408 & 0.154 & 0.137 & 0.209 & مستوى معنوية (ت) \\
\hline
\end{tabular}
الد صدر : جمعت وح سبت من بيانات قاعدة البيانات الإح صائية لمنظمة الأغذية و الزر اعة للأمم المتحدة، أخر دخول: 30 أغسطس 2020. 
كما يوضح ذات الجدول أن هناك انخفاضاً معنوياً في متوسط عدد مذبوحات الأبقار و الجاموس خلال الفترة 2012-2016 مقارنة بمتوسطها في الفترة الأولى. و على الرغم من ثبات أعداد الماشية الحلابة، إلا أن الكمية المنتجة من الألبان خلال الفترة من 2000-2016 قد زادت زيادة طفيفة معنوية إحصائياً تقدر بنحو 1.9\% سنوياً، كما هو موضح بالجدول رقم (3) بالملدق.

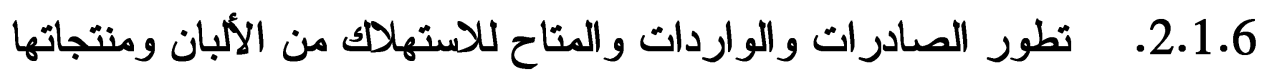
يوضح الجدول رقم (3) بالملحق أيضاً ثبوت المعنوية الإحصائبة للنمو في كمية الصادرات من الألبان ومنتجاتها خلال الفترة 2001-2019، حيث بلغ معدل الزيادة نحو 12.8\% سنوياً. كما يتبين من ذات الجدول عدم معنوية الزيادة في كلٍ من الواردات من الألبان ومنتجاتها، و المتاح للاستهلالك منها خلال الفترة المذكورة. هذا، وقد بلغ معدل الاكتفاء الذاتي من الألبان ومنتجاتها خلال متوسط الفترة من 2000 حتى 2016 نحو 92\%، بحد أدنى 76\% عام 2000، وبحد أقصى بلغ حو الي 116\% عام 2010 (جدول رقم (2) بالملحق).

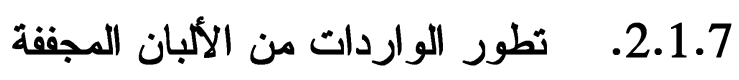

في عام 2019، استوردت مصر حوالي 114 ألف طن من الألبان المجفة بأنو اعها المختلفة (البنود الجمركية 040210، 040221)، بإجمالي قيمة بلغت حو الي 361 مليون دو لار، كما هو موضح في الجدول رقم (4) بالملحق. ويوضح الجدول رقم (5) بالملدق أن كميات وقيم الواردات من الألبان

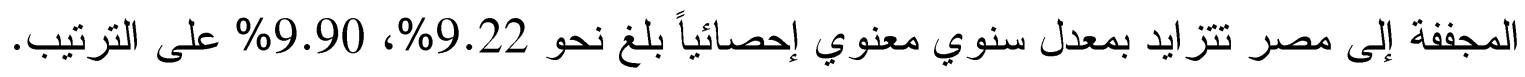

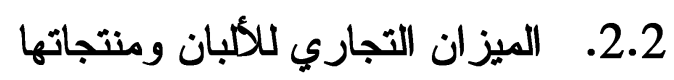

يتبين من الجدول رقم (6) بالملدق أن الميزان التجاري للألبان ومنتجاتها عام 2019 قد حقق عجزاً مقداره حو الي 336 مليون دو لار • وقد حققت أربع مجموعات رئيسة للألبان ومنتجاتها عجزاً مستمراً في إجمالي الميزان التجاري للمنتجات التي تتضدنها في 2015، وحتى 2019، في حين لم بحقق فائضاً في الميزان التجاري إلا مجموعتين. وقد كانت أكثر المجموعات التي شهدت عجز اً في ميز انها التجاري: مجموعة اللبن و القشدة غير المركزة أو المضاف إليها سكر أو أي مادة أخرى للتحلية (البند الجمركي 0402)، و التي تتضمن الأصناف المختلفة من اللبن المجفف، وبروتين اللبن، و الكازينات، وغيرها التي تستوردها مصانع الألبان لاسترجاعها كبديل للبن الخام. أما ثاني أكثر المجموعات عجزاً في ميزانها التجاري، فكانت مجموعة الزبدة بأنواعها والسمن والزيوت الأخرى المشتقة من الدهن، والتي يتم 
استيرادها من قبل مصانع الألبان أيضاً لاستكمال عمليات استرجاع الألبان المجفة منزوعة الدسم في أغلب أحو الها، وصو لاًً إلى لبن معاد تركيبه.

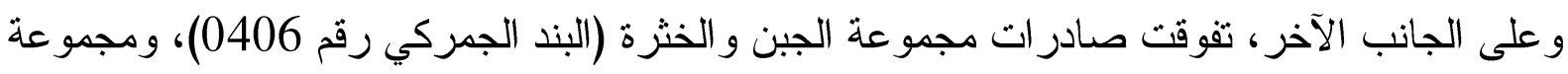
اللبن و القثدة غير المركزة أو بدون إضافة سكر أو أي مادة أخرى للتحلية (البند الجمركي رقم 0401) على وارداتها.

\subsection{1.الميزة النسبية للألبان المصرية ومنتجاتها}

و على الرغم من العجز في الميزان التجاري للألبان ومنتجاتها، إلا أنه وفقاً لمؤشر الميزة النسبية الظاهرة أو دليل بالاسا- معادلة رقم (1)، يتضح من الجدول رقم (2) أن للألبان ومنتجاتها المصرية ميزة نسبية في أسواق التصدير، نزيد في الأسواق الدولية للجبن و الخثرة، خاصةً في أسواق الجبن المطبوخ. كما لها أن لمصر ميزة نسبية أيضاً في أسواق الجبن الطازج غبر المسوى، والجبن الأخرى الجافة والنصف جافة، وإن كانت بمقدار أقل بكثير من تلك الميزة النسبية التي تتمتع بها الجبن المطبوخ المصرية في الأسواق الدولية لهذا الصنف من الجبن.

\section{جدول 2: مؤشر القيمة النسبية الظاهرة للألبان ومنتجاتها في مصر عام 2019}

(القيمة بالألف دو لار)

\begin{tabular}{|c|c|c|c|c|c|}
\hline والنصف جاف الجاف & الجبن الطازج & الجبن المطبوخ & الجبن والخثرة & ومنتجاتها & \\
\hline 46174 & 64724 & 138,594 & 253,368 & 303,520 & قيمة صادرات مصر من المنتج عام 2019 \\
\hline \multicolumn{5}{|c|}{$30,632,553$} & قيمة الصادرات الكلية المصرية عام 2019 \\
\hline $18,958,285$ & $7,335,470$ & $2,663,060$ & $32,203,677$ & $79,900,400$ & الصادرات الكلية للعالم من المنتج عام 2019 \\
\hline \multicolumn{5}{|c|}{$18,754,622,224$} & الصادرات الكلية للعالم عام 2019 \\
\hline 1.49 & 5.40 & 31.86 & 4.82 & 2.33 & قيمة دليل بالاسا \\
\hline
\end{tabular}

المصدر : جمعت وحسبت اعتماداً على بيانات خريطة التجارة، تم الاخول إليها أخر مرة في 23 أغسطس 2020.

\subsection{2. تحليل صادرات الألبان ومنتجاتها}

لوحظ عموماً، أن وجهة الصادر ات المصرية في معظمها تستهدف بلدان عربية أو إفريقية، والقليل من البلدان الأخرى. وكان الجبن المطبوخ، غير المسحوق أو المبشور (بند جمركي ذللك، حيث نم تصدير 80\% منها إلى خمس دول عربية عام 2019، هي: ليبيا، المملكة العربية

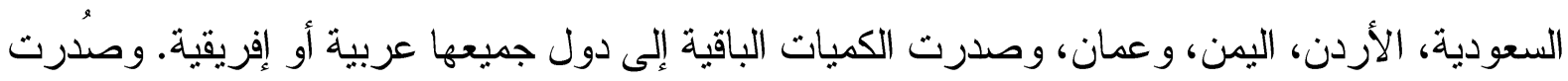
منتجات هذا البند الجمركي إلى 22 دولة أخرى خلال الخمس سنو ات السابقة للار اسة جميعها عربية أو 
إفريقية ما عدا: بروناى، سريلانكا، قبرص، ماليزيا، هولندا، الباكستان، الفلبين، سلوفينيا، السويد، تايلاند

.(Trade Map, 2020)

وقد بلغ متوسط المسافة التي يقطعها المنتج المصري من الألبان ومنتجاتها إلى أسواق التصدير نحو 1691 كم، بحد أدنى 388 كم في حال الحليب والقتدة في صورة صلبة، محتوى دهني بالوزن 1.5 => حال منتجات الحليب و القتشدة التي تحنوي دهون بالوزن >= 1\%، غير مركزة ولا تحتوي على سكر مضاف، (بند جمركي رقم 040110). وربما عكس انخفاض المسافة التي تقطعها الصادرات المصرية من الألبان ومنتجاتها أنها نستهدف بالأساس الأسو اق الإقليمية الأقرب: العربية والأفريقية. وقد بلغ إجمالي قيمة الصادر ات من الألبان ومنتجاتها في عام 2019 حو الي 304 مليون دو لار، تتكون في معظمها من الجبن والخثرة (83\%) كما هو موضح بجدول رقم (6) بالملحق. ويؤكد ذلك جدول رقم (7) بالملدق الذي يعرض ترتيب أكثر منتجات الألبان المصرية نو اجداً في أسواق التصدير، حيث بلغت قيمة الصادرات المصرية من الجبن المطبوخ نحو 139 مليون دولار تمثل حوالي 55\% من قيمة صادرات الجبن، و46\% من قيمة الصادرات الكلية من الألبان ومنتجاتها، ونحو 5.0\% من قيمة الصادرات المصرية الكلية في عام 2019 (Trade Map, 2020).

\subsection{3 تحليل واردات الألبان ومنتجاتها}

يوضح جدول (8) بالملحق ترنيب البنود الجمركية الأكثر مساهمةً في العجز في الميزان التجاري

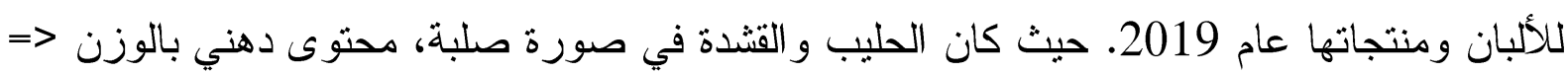
1.5٪ (البند الجمركي 040210) هو الأكثر مساهمة في قيمة واردات الألبان ومنتجاتها في ذات العام. حيث بلغت كمية واردات مصر من هذا البند الجمركي نحو 85 ألف طن، بقيمة 193,053 مليون دو لار 6 مثلت نحو 30.18\% من إجمالي قيمة الواردات من الألبان ومنتجاتها البالغة نحو 640 مليون دو لار في ذات العام. وتُعد مصر في الترتيب 12 عالمياً كأهم البلدان المستوردة لمنتجات هذا البند الجمركي. و لا تُصدر مصر من منتجات هذا البند الجمركي سوى ما قيمته 6 آلاف دو لار، ليبلغ العجز 
في الميزان التجاري لهذا البند بمفرده نحو 193.047 مليون دو لار تمثل 57.4\% من إجمالي العجز في الميزان التجاري للألبان ومنتجاتها في ذات العام.

وقد تم دفع 55.5\% من قيمة الواردات من الحليب و القتّدة في صورة صلبة، محتوى دهني بالوزن >>

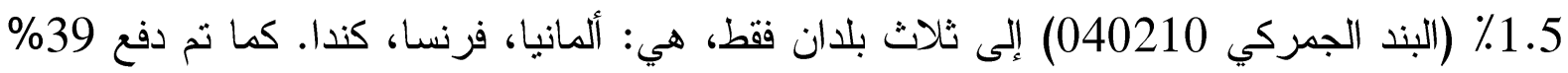
من قيمة الواردات من هذا المنتج إلى 9 بلدان أوروبية أخرى، هي: المملكة المتحدة، السويد، فنلندا،

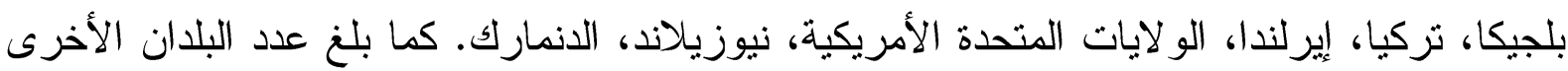
التي وردت منتجاتها من هذا البند الجمركي إلى مصر 15 دولة في عام 2019 نقع جميعها في أوروبا ما عدا المملكة العربية السعودية، سنغافورة، والهند. يمتاز هذا البند بنو افر أسو اق متعددة له، و لا تبعد مسافة التوريد نسبياً، و التي تبلغ في المتوسط حو الي 4469 كم فقط.

وعلى نفس المنوال، كان البند الجمركي 040221، الحليب و القشدة في صورة صلبة، محتوى دهني بالوزن> 5. 1\%، غير محلى، ثالث أكثر البنود الجمركية مساهمة في العجز في الميزان التجاري للألبان ومنتجاتها عام 2019، وقد تتضمن هذا البند وفقاً لموقع خريطة التجارة عام 2018، عدداً من البنود

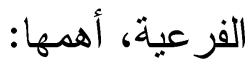

- الحليب، في صورة مسحوق أو حبيات أو أي صور صلبة أخرى، بمحتوى دهني بالوزن، يزيد عن 1.5٪ لا يحتوي على سكر مضاف أو مو اد تحلية أخرى، في عبوات 20 كجم و أكثر (بند جمركي 0402219190)، وبلغت واردات هذا البند بمفرده حو الي 92 مليون دو لار عام 2018. وجدير بالذكر أن البند الجمركي 040221، ذو متوسط تعريفة جمكية (4.5\%)، وقد شهدت الفترة من 2015-2019 انخفاضاً ملحوظاً في معدل نمو كمية وقيمة الواردات منه. كما أن منوسط المسافة التي تقطعها الكميات المستوردة من هذا المنتج قد بلغت نحو 13775 كم، حيث تم استير اد 73\% من قيمة هذا البند من نيوزيلندا، ونم استير اد الباقي من 17 دولة أخرى ثقع جميعها في أوروبا ما عدا أوروجو اي، وسنغافورة، والهند.

أما الزبدة (باستثناء الزبدة المجففة و السمن) (البند الجمركي 040510)، فعلى الرغم من انخفاض النمو

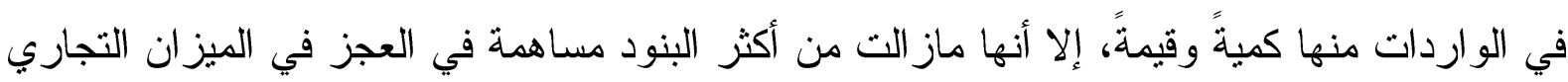
للألبان ومنتجاتها. وعلى الرغم من ذلك أيضاً، فإن متوسط التعريفة الجمركية لهذا البند ليس مرتفعاً (1.9\%)، مما يعنى أن السياسة الجمركية تشجع استير اد هذا البند، ربما لعدم توفر البديل المحلى. ويعد هيد 
منوسط المسافة الذي يقطعها هذا المنتج كبيرة نسبياً (8898 كم)، حيث نم استير اد 69\% من هذا البند من نيوزيلندا، و الهند عام 2019. وتأكيداً على عجز السوق المحلى عن توفير الدهون الحيوانية اللازمة لأغر اض تصنيع منتجات الألبان، تم استير اد دهون وزيوت مشتقة من الحليب (البند الجمركي 040590) بنحو 52 مليون دو لار عام 2019، قطعت مسافة كبيرة من بلدان منشأها قُرت بحو الي 13845 كم 134 حتى وصولها إلى مصر · حيث تم استير اد هذا البند بصفة أساسية من نيوزيلندا (79\%) عام 2019، وقامت سبع دول أخرى بتوريد الكميات الباقية، هي: فرنسا، هولندا، أوغندا، الهند، ألمانبا، بلجيكا، و أستر اليا. وتم استير اد هذا البند في الخمس سنوات الأخيرة من 13 دولة أقربهم جغر افياً سوريا، كينيا،

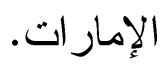

وتتضمن قائمة أكثر البنود الجمركية تسبباً في العجز في الميزان التجاري للألبان ومنتجاتها بندين

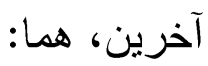
- منتجات البند الجمركي رقم (040690): الجبن، باستثناء الجبن الطازج بأنو اعه، بما في ذلك جبن مصل اللبن و اللبن الرائب و الجبن المطبوخ و الجبن ذات العروق الزرقاء و الجبن الأخرى المحتوية على عروق من إنتاج "بنسيليوم روكفورني" و الجبن المبشور أو المسحوق. وتشمل منتجات هذا البند في معظمها الجبن الجاف و النصف جاف، و التي بلغت قيمة الو اردات منها نحو 92,5 مليون دو لار. - منتجات البند الجمركي رقم (040490): وهي منتجات تتكون من مكونات الحليب الطبيعي، سواء كانت أو لم تكن محلاة، طالما ليست مذكورة في موضع آخر ـوقد بلغت قيم الواردات من هذا البند الجمركي حو الي 62 مليون دو لار عام 2019.

\section{3. استر اتيجية نوطين سلسلة توريد الألبان ومنتجاتها في مصر : السياسات و البرامج}

يمكن القول إن للألبان المصرية ومنتجاتها ميزة نسبية ظاهرة في أسو اق التصدير ، وخاصة في صناعة الجبن والخثرة. ولن يكون ذلك إلا لأنها تتمتع بميزة نسبية محلياً. وفي ضوء التحليل السابق لسوة لسلسلة توريد الألبان ومنتجاتها في مصر، ومكن استتناج التالي: - - تعاني معظم الثروة الحيوانية من الأبقار و الجاموس من عدم توفر الأعلاف كماً ونوعاً، ونقص الرعاية البيطرية، مما يؤدى إلى انخفاض إنتاجيتها، التي تصل إلى نحو 1 طن سنوياً فقط للأبقار البلدية، 1.7 طن/سنة للجاموس، في مقابل 6 طن/سنوياً للأبقار الأجنبية المتخصصة. 
- معظم الكميات المنتجة من الألبان الخام في مصر تتم في البيوت الريفية، تحت ظروف بيئية غير مناسبة لإنتاج منتج يتو افق مع منطلبات الجودة، وسلامة الغذاء. وتفقتد عمليات جمع الألبان وتخزينه ونقله الاشتر اطات الصحية المناسبة، فيصل إلى المعامل البلدية في القرى وقد تدهورت

$$
\text { خو اصه الحسية و الكيميائية و الميكروبيولوجية. }
$$

- ميتركز إنتاج الألبان في خمس محافظات في الوجه البحري، هي: البحيرة، المنوفية و الثرقية و الغربية و الدقهلية، بالإضافة إلى ثلاث محافظات في الوجه القبلي، هي: الفيوم، بنى سويف، المنيا. كما ينركز نصف إنتاج الجبن الأبيض في ثلاث محافظات، هي: الدقهلية، و الإسكندرية، ودمياط. كما يُنتج أكثر من الثلث من هذا المنتج الرئيسي في ثلاث محافظات أخرى، هي: الثرقية، القليو بية، و الجيزة. - إنتاج الألبان في مصر بمفرده لا يكفي لسد احتياجات الاستهلاك، ويتم استير اد الألبان المجففة و الزبد لتعويض العجز في الإتتاج المحلى من اللبن الخام بما تقارب قيمته 370 مليون دولار عام 2019. - بلغت كمية الألبان المجفة المستوردة في عام 2019 حوالي 114 ألف طن (تكافئ حوالي مليون طن من اللبن المعاد تركيبه، بمعامل استرجاع 1 لبن بودرة/ 9 ماء). - بلغت كمية الجبن الجاف و النصف جافة المسنوردة نحو 22,7 ألف طن (تكافئ حوالي 182 ألف طن من اللبن الخام، بمعامل تحويل 8 كجم لبن إلى 1 كجم جبن). - في الوقت الذي تزيد فيه الككيات الموردة إلى مصر من الألبان المجفقة بمعدل 9-10\% سنوياً، بلغ معدل الزيادة في الإنتاج من الألبان الخام نحو 1.9\% فقط، مما لا ينباً بإمكانية "إحلال الو اردات" من الألبان المجفةة بالألبان الخام المنتجة محلياً في المدى القصير، إذا استصرت سلسلة

$$
\text { التوريد بوضعها الحالي. }
$$

- يفتقر قطاع الألبان ومنتجاتها إلى عدد من الصناعات الهامة المغذية له غير المنتجة محلياً، وتهدد في حال حدوث اضطر ابات في سلاسل التوريد العالمية إلى تعريض هذه الصناعة إلى إلى مخاطر كبيرة، ومن أهم هذه الصناعات: صناعة المنفحة والبادئات الميكروبية، صناعة الأحماض العضوية مثل حمض الستريك واللاكتيك و البروبيونيك وأملاحهم المستخدمة على ونى نطاق و اسع في صناعات غذائية عديدة. كما تحتاج صناعة المعدات والآلات المحلية إلى تطوير خاصةً ما يتعلق بتصنيع لوحات التحكم الإلكترونية أو المو اتير و المضخات. 
وفي ضوء ذلك يستهدف هذا الجزء من الدراسة، وضع أهداف استر اتيجية لمزيد من توطين صناعة الألبان ومنتجاتها في مصر • و اقتز احات الآليات و السياسات التي من شأنها تحقيق تلك الأهداف.

\section{1. الأهداف الاستر اتيجية لتوطين سلسلة توريد الألبان ومنتجاتها في مصر}

3.1.1. الوصول بإنتاج الألبان من الماشية التقليدية إلى حو الي 7.5 مليون طن خلال 5 سنو ات،

و إلى نحو 11 مليون طن خلال 10 سنو ات. (على أساس زيادة إنتاجية الماشية التقليدية

$$
\text { بمعدل 10\% سنوياً) }
$$

3.1.2. الوصول بإنتاج الألبان من الماشية الأجنبية المتخصصة إلى 1.8 مليون طن خلال 5 سنوات، و6.8 مليون طن خلال عشر سنوات. (على أساس الوصول بأعداد الأبقار الأجنبية الحلابة إلى 300 ألف خلال خمس سنوات، ومليون رأس خلال عشر سنوات) 3.1.3. تحقيق فائض في الميزان التجاري لهذه المجموعة خلال 10 سنوات. (على أساس

$$
\text { تخفيض العجز في الميزان التجاري بنسبة 10\% سنوياً) }
$$

3.2. الأهداف النكتيكية

3.2.1. زيادة إنتاجية الماشية التقليدية بمعدل 10\% سنوياً.

3.2.2. الوصول بأعداد الأبقار الأجنبية "الحلابة" إلى 300 ألف خلاد خمس سنواته، ومليون

$$
\text { رأس خلال عشر سنوات. }
$$

3.2.3. خفض العجز في الميزان التجاري 10\% سنوياً.

3.3. أهم السياسات المطلوبة لتحقيق الاستر اتيجية

$$
\text { 3.3.1 - السياسة الزر اعية }
$$

3.3.1.1. نوفير الأعلاف بالكميات والأسعار المناسبة لتغذية الماشية الحلابة في أماكن

$$
\text { التصركز لإنتاج الألبان }
$$

3.3.2. - السياسة البيطرية

3.3.2.1 التحسين الور اثي للسلالات التقليدية

3.3.3. السياسة الصناعية

3.3.3.1. تخفيض تكاليف استخدامات الطاقة.

$$
\text { 3.3.4 السياسة التجارية }
$$

3.3.4.1. خفض منوسط عدد الأميال التي تقطعها واردات الألبان ومنتجاتها إلى مصر 
3.3.4.2. خفض معامل تركيز دول توريد الألبان ومنتجاتها إلى مصر.

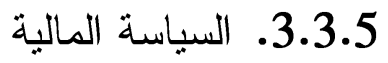

3.3.5.1 إعفاءات جمركية على الواردات من المانشية الحلابة الأجنبية. 3.3.5.2 3. إعفاءات جمركية على الواردات من معدات مر اكز تجميع الألبان.

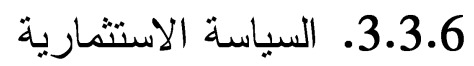

3.3.6.1. إعفاءات ضريبية لمشروعات إنتاج الجبن الجاف، ومنتجات الشرش، والمنفحة و البادئات الميكروبية، تصنيع معدات الألبان في المناطق الصناعية برج العرب ودمياط الجديدة.

3.3.6.2. تحمل الدولة جزء من تكاليف توصيل المرافق إلى المشروعات المذكورة في و

3.4. البر امج التنفيذية يُدعى لتثكيل لجنة فنية عليا "لتوطين سلاسل توريد الألبان"، تسمى فيما يلى "اللجنة العليا"، بعضوية ممثلين فنيين من مجلس الصناعة للتكنولوجيا و الابتكار بوزارة الصناعة و التجارة، وزارة الاستثمار و المناطق الحرة، وزارة الزراعة واستصلاح الأراضي، هيئة التتمية الصناعية، جهاز تتمية المشروعات الصغيرة و المتوسطة، الهيئة القومية لسلامة الغذاء، و أكاديمية البحث العلمي و التكنولوجيا، بالإضافة إلى ممثلين من وزارة التخطيط و المتابعة، ووزارة المالية للإنشراف على تتفيذ الاستر اتيجية التي تتضمن برنامجين، هما: (1) برنامج زيادة إنتاج الألبان وتحفيز الطلب على منتجات الألبان التقليدية. (2) برنامج توطين الجبن الجاف و النصف جاف وأهم الصناعات المغذية

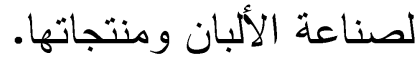
ويتو افق هاذين البرنامجين مع الأهداف الأساسية لاستر اتيجية التتمية الزراعية المستدامة 2030 أرقام: (3/4/2: تدعيم القدرة التنافسية للمنتجات الزر اعية و التحديات التي تو اجهها: 4/4/2: تحقيق معدلات أعلى للأمن الغذائي من السلع الاستر اتيجية: 2/4/4/2: تطوير الأنماط الاستهلاكية لصالح تحسين مستويات التغذية: 3/4/4/2: الحد من الفاقد التسويقي لسلع الغذاء). ${ }^{7}$ كما ينو افق برنامجي 
الاستر اتيجية المقترحة مع أهداف استر اتيجية رؤية مصر 2030، وخاصةً فيما يتعلق بالهدفين الثالث والرابع لمحور الاقتصاد المعنيين بتعزيز التتافسية والتتوع وتعظيم القيمة المضافة. 8 3.4.1 برنامج زيادة إنتاج الألبان من الماشية الحلابة التقليدية والأجنبية وصف البرنامج: يستهدف البرنامج تحقيق فائض في إنتاج الألبان المحلية من الماشية الحلابة التقليدية (الأبقار البلدية والجاموس)، وكذلك من الأبقار الأجنبية. وينكون البرنامج من خمسة مشروعات: (1) مشروع تطويز شبكة من مر اكز ونقاط لتجميع الألبان من القطاع التقليدي. (2) مشروع تطوير إنتاج الألبان من المزارع المتخصصة. (3) مشروع الدعم الفني ونقل التكنولوجيا لتطوير إنتاج وتصنيع الألبان ومنتجاتها. (4) مشروع "تثبع" كميات الإنتاج وجودة وسلامة الألبان ومنتجاتها. (5) مشروع تحفيز الطلب على منتجات الألبان التقليدية. ويتو افق هذا البرنامج مع أهداف المشروع الوطني لنطوير مر اكز التجميع، ويعمل على تعزيز استدامة مر اكز تجميع الألبان من خلال نظوير منظومة البحوث و التطوير والابتكار و التتبع، مع المساعدة في تغيير أنماط الاستهلاك لتصبح أكثر ارتباطاً بأحد المجموعات الغذائية ذات القيمة الغذائية المرتفعة. 3.4.1.1. مشروع تطوير شبكة من مر اكز ونقاط لتجميع الألبان من القطاع التقليدي بهي

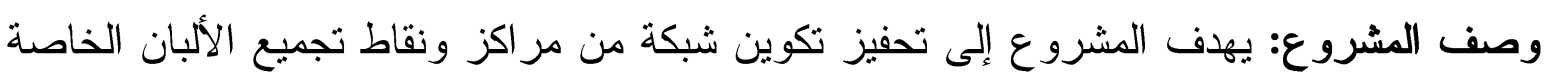

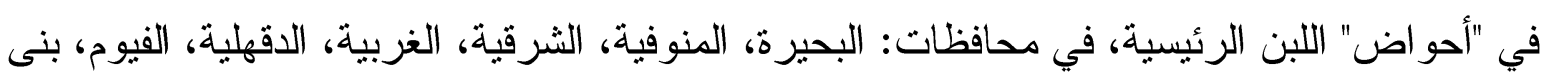
سويف، المنيا. ومن شأن مر اكز التجميع هذه في حال التوسع في إنثاءها المساهمة في تحسين إنتاجية الماشية الحلابة من خلال الخدمات التي تقدمها، و المتعلقة بصحة وتغذية الحيو ان. ولنجاح هذه المر اكز يجب أن يكون هناك تعاقد على توريد منتجاتها مسبقاً لمدد محددة مع شركات تصنيع ألبان لضمان الاستمر ار في عمليات استقبال وحفظ وتوريد الألبان دون توقف.

\section{العناصر الأساسية للمشروع}

- ينشأ 10 مر اكز تجميع سنوياً في كل من البحيرة و الثرقية و الغربية و الدقهلية، الفيوم، بنى سويف،

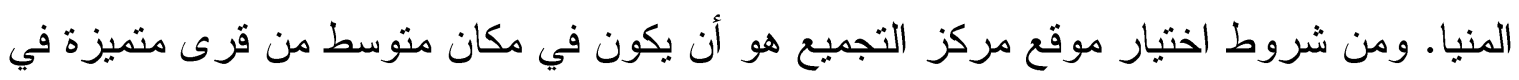


إنتاج اللبن، وبالقرب من الطريق الرئيسي وتكون سعة استقباله للألبان تتر اوح ما بين 10 إلى 20 طن. - يُلحق بهذه المر اكز نقاط للتجميع (بسعة من 500 كجم إلى 2 طن) تتو اجد في القرى المتميزة في إنتاج الألبان المحيطة بمركز التجميع. - تتوفر بكل مركز تجميع سيارة مزودة بتتك -حفظ حرارى- سعة 5 طن، لكى تستخدم في نقل اللبن من نقاط التجميع في القرى إلى المركز الرئيسي. وتستخدم كذلك في نقل اللبن من مراكز التجميع إلى مقر المصانع المتعاقد معها على توريد الألبان التي تم تجميعها. - يلحق بمركز التجميع وحدة تصنيع للطوارئ مصممة لتصنيع الجبن الدمياطي "الخزين" في حال رفض الألبان لأى سبب من قبل المصانع المنعاقد عليها. - تقدم تلك المر اكز حزم خدمات لمنتجي الألبان في القرى المتميزة لإنتاج الألبان تثمثل في علائق منو ازنة لتغذية الماشية الحلابة بأسعار التكلفة، وخدمات بيطرية تتضمن كثف دوري على الماشية، وتقديم الأدوية البيطرية الموثوقة بالأسعار الرسمية، وتقديم خدمات التلقيح الصناعي 9. - بمكن الاسترشاد بخمس خطط تجارية Business Plans على طول سلسلة التوريد للألبان ومنتجاتها أنتجها مشروع تحسين الدخل والاقتصاد الريفي، بتعاون بين مركز تكنولوجيا الصناعات الغذائية والتصنيع الزر اعي مع جهاز تتمية المشرو عات الصغيرة و المنوسطة -الصندوق الاجتماعي

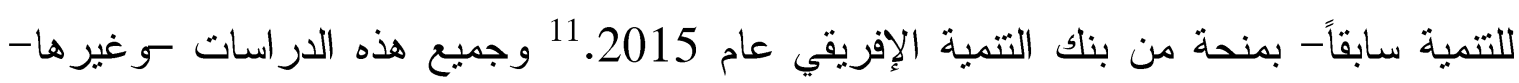
متوفرة بالإدارة الزر اعية بجهاز تتمية المشروعات الصغيرة و المتوسطة، ويمكن تحديث بياناتهم. مسئوليات وآلية التنفيذ: تتولى اللجنة الفنية العليا لتوطين سلاسل توريد الألبان: أ- تحديث دراسات الجدوى عن سلاسل التوريد السابق الإشارة إليها بحيازة جهاز تتمبة المشروعات الصغيرة و المتوسطة.

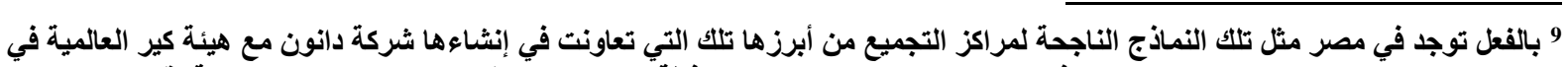

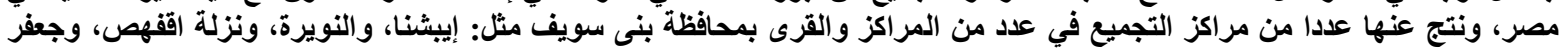

وغيرها. 10 قام بإعدادها الباحث بالاشتراك مع أ.د. عثمان عيطة أستاذ الألبان بكلية الزراعة جامعة عين شمس، وأ.د. هاشم حامد عبد الرحمن أستاذ الإتتاج الحيواني بالمركز القومي للبحوث.

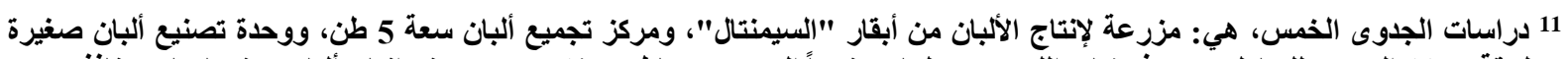

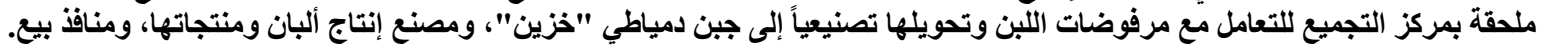


ب-تحديد المر اكز "الإدارية" المقترح إقامة مراكز تجميع الألبان فيها في محافظات البحيرة، المنوفية

$$
\text { و الثرقية و الغربية و الدقهلية، و الفيوم، وبنى سويف، و المنيا. }
$$

ج-تغذية الخريطة الاستثمارية المصرية بدراسات الجدوى المحدثة عن فرص الاستثمار في مراكز

$$
\text { التجميع استجابة لمبادرة السيد رئيس الجمهورية. }
$$

د- الإعلان عن نسهيلات للقطاع الخاص و الحكومي و الاستثماري و الأفراد الر اغبين في الاستثمار في مر اكز التجميع في الأماكن المحددة على الخريطة الاستثمارية، تتضمن: تسهيل إجر اءات تمويل الأصول من جهاز تتمية المشروعات الصغيرة و المتوسطة تشمل تمويل 75 من قيمة الأصول (المعدات ورأس المال العامل)، على أن يقوم المستثر بتحمل تكاليف

$$
\text { إعفاء ضريء الأر اضي و المباني. }
$$

تسهيل إجر اءات التراخيص من خلال شباك اليوم الواحد التابع لهيئة التتمية الصناعية.12. تدريب مدير المشروع بدورات تدريبية مقابل رسوم رمزية يدفعها المستثمر تنثمل وليس حصر اًإدارة المشروعات، تكنولوجيا الألبان السائلة، مراقبة الجودة بمر اكز تجميع الألبان. تتم بجهاز تنمية المشروعات الصغيرة والمنوسطة، ويقوم بها خبر اء من معهد التخطيط القومي، ومركز تكنولوجيا الصناعات الغذائية والتصنيع الزراعي، ومعهد بحوث وتكنولوجيا الأغذية بمركز

$$
\text { البحوث الزر اعية و الجهات الأخرى ذات الصلة. }
$$

إثر اف مركز تكنولوجيا الصناعات الغذائية والتصنيع الزراعي، والجهات الأخرى ذات الصلة على عملية تأهيل مركز التجميع و النقاط المحيطة للتو افق مع منطلبات الهيئة القومية لسلامة الغذاء مقابل رسوم رمزية يدفعها المستثر . قيام الهيئة القومية لسلامة الغذاء بالتقنيش على مركز التجميع و النقاط التابعة له، للتحقق من

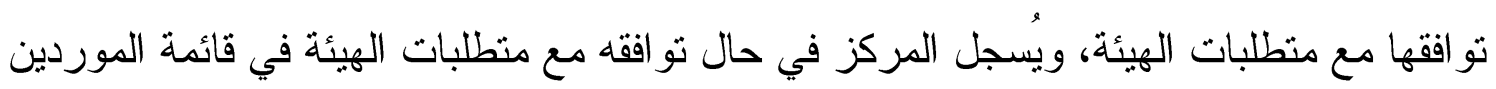
المعتمدين في جمهورية مصر العربية لتوريد الألبان.

12 أو علي الأقل استخراج رخصل تثثغيل من الوحدات المحلية بالمحافظات في ضوء الجدل حول ما إذا كانت مراكز التجميع نُعد نثاطاً صناعياً أم لا وفقاً لهيئة التنمية الصناعية. 
تُشهل اللجنة وتُشرف على عمليات التعاقد القانوني على توريد الألبان التي يقوم بجمعها المركز

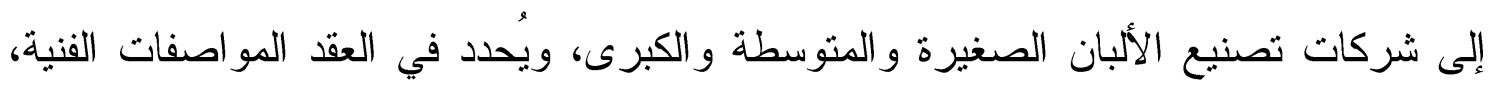
و الأسعار، و الجزاءات، و الإثابة في حال الجودة الأكثر من المطلوبة.

\subsubsection{2 مشروع تطوير إنتاج الألبان من المزارع المتخصصة}

وصف المشروع: يهدف هذا المشروع التوسع في مزارع إنتاج الألبان التي تستخدم السلالات الأوروبية المتخصصة في إنتاج الألبان مثل الفريزيان، و السيمنتال في الأماكن المناسبة بالقرب من المناطق الصناعية خاصة: برج العرب، العاشر من رمضان، العبور، السادس من أكتوبر، دمياط الجديدة. مع تقديم الحو افز الاستثارية الكفيلة بجذب الاستثمارات المحلية و الأجنبية إلى هذا القطاع. 13

\section{العناصر الأساسية للمشروع}

- ينشأ سنوياً عدد 20 مزرعة ذات سعة من 10 إلى أقل من 25 رأس في كل من النوبارية، و الإسكندرية، الفيوم، و الثرقية، و الغربية، و الجيزة، و القليوبية، و الدقهلية، و البحيرة، و الدنوفية. - ينشأ سنوياً عدد 10 مزارع ذات سعة من 25 إلى أقل من 50 رأس في كلٍ من النوبارية، و الإسكندرية، و الفيوم، و الثرقية، و الغربية، و الجيزة، والقليوبية، و الدقهلية، و البحيرة، و المنوفية،

ودمياط.

- ينشأ سنوياً عدد 5 مزارع ذات سعة أكبر من 50 رأس في كل من النوبارية، والإسكندرية و الفيوم، و الثرقية، و الغربية، و الجيزة، و القليو بية، و الدقهلية، و البحيرة، و المنوفية، و الو ادي الجديد.

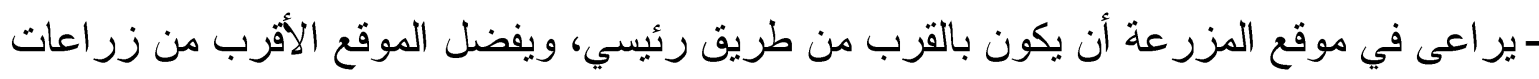
توفر العلائق الخضر اء، ومن مصانع الأعلاف في المحافظات المختارة. - جميع المزارع مزودة بمحالب آلية، وتتكات تبريد تتتاسب مع السعة الإنتاجية. - ير اعى أن تتتاسب مساحة المزرعة فنياً مع أعداد الحيو انات، وأن تصمم بما يضمن تحقيق رفاهية الحيوانanimal welfare ، من حيث مساحة الظل، ونظافة الآسرة "الفرش"، وتوفر المياه النظيفة الكافية، وتوازن العلائق غذائياً، وتوفر الرعاية الصحية والأدوية البيطرية. 
-وير اعى أن تتضمن المز ارع -كلما أمكن ذلك- حظائر للماشية الحلابة، وأخرى للو لادة و الرضاعة،

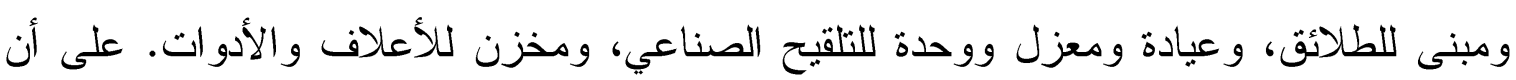
تراعى المساحة الزيادة المنوقعة في قطيع الماشية الناتج عن الو لادات.

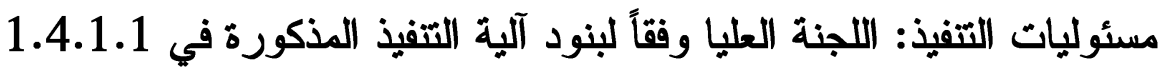

3.4.1.3. مشروع الابتكار ونقل التكنولوجيا في قطاع الألبان ومنتجاتها

وصف المشروع: يهذف المشروع إلى ربط البحث العلمي بصناعة الألبان ومنتجاتها، بحيث تقوم أكاديمية البحث العلمي و التكنولوجيا بطر ح عدد من المشرو عات البحثية سنوياً نستهدف حل مشكلات إنتاج وتصنيع الألبان من خلال حلول مبنكرة، نوظف فيها الخبرات و المعارف العلمية و التقنية لفرق عمل فنية متعددة التخصصات من الجامعات و المر اكز البحثية المختلفة ذات الصلة.

\section{العناصر الرئيسية للمشروع}

- تبحث اللجنة العليا أهم المشكلات التي تو اجه قطاع الألبان ومنتجاتها من خلال تغذية راجعة من الخبر اء الفنيين باللجنة في ظل التواصل المستمر مع العاملين بالقطاع. - يتم تحديد قائمة بالمشكلات التي تواجه الصناعة، ويرجى تقديم حلول تقنية مبنكرة لها، و إرسال القائمة إلى أكاديمية البحث العلمي و التكنولوجيا. - نطرح أكاديمية البحث العلمي و التكنولوجيا 5 مشروعات سنوياً في موضوعات نستهدف حل

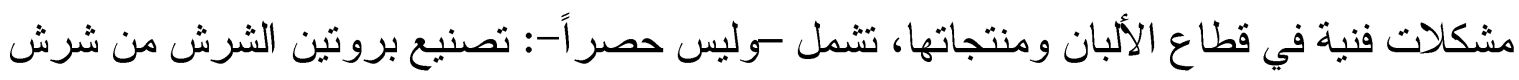
اللبن عالي الحموضة و المرتفع في نسبة الملح و العدد الكلى للميكروبات، تطوير صناعة المنفحة

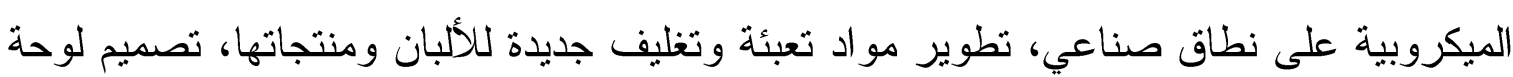
تحكم آلي مبتكرة لتسهيل عمليات تصنيع الجبن الجاف، حلول مبتكرة لزيادة إنتاجية الماشية الحلابة تحت الظروف المصرية.

- يُطلب تقديم عروض فنية ومالية للمشرو عات البحثية Call for proposals، يُدعى إليها الباحثين وذوي الخبرة العملية في شتى فروع علوم وتكنولوجيا الألبان، والعلوم الأخرى ذات الصلة، مثل:

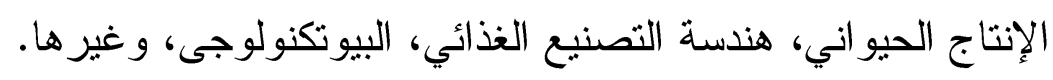


- تُسند أكاديمية البحث العلمي و التكنولوجيا مسئولية تحكيم المقترحات البحثية إلى متخصصين، وفقاً للإجر اءات المتبعة بالأكاديمية.

- تتاقش المقترحات المقدمة من الباحثين -المرشحين للقبول- علناً، في حضور أعضاء اللجنة العليا لبرنامج زيادة الإنتاج من الماشية التقليدية و الأجنبية. - يتم قبول المقترحات البحثية التي يتوقع أن تقدم حلو لاً أكثر ابتكار أ لتحسين الإنتاجية، وتقليل الفاقد، وزيادة القيمة المضافة من الموارد المتاحة.

مسئوليات التنفيذ: أكاديمية البحث العلمي والتكنولوجيا بالتتسيق مع اللجنة العليا 3.4.1.4. مشروع "تثبع" كميات الإنتاج وجودة وسلامة الألبان ومنتجاتها وصف المشروع: يستهدف المشروع ربط سلسلة توريد الألبان الخام المنتجة في مراكز التجميع و المز ارع المعتمدة من الهيئة القومية لسلامة الغذاء و المصانع المسجلة بقاعدة بيانات تدير ها الهيئة من أجل تتبع حركة الإنتاج المحلى من اللبن الخام، ومراقبة معايير جودته وسلامته من المخاطر الغذائية. ويكون لإدارة مر اكز التجميع و المزارع القدرة على الدخول على قاعدة البيانات لتسجيل مصادر وكميات الألبان الواردة إليها، وإلى من توجهت هذه الكميات، و الكميات الفائضة و المتاحة

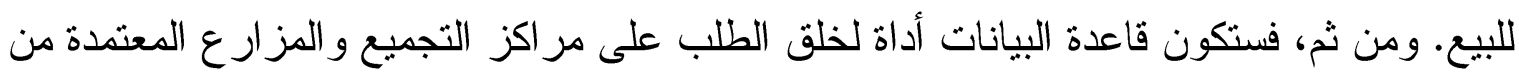
الهيئة القومية لسلامة الغذاء، حيث تلزم الهيئة مصانع الأغذية بالتعامل فقط مع موردين معتمدين

كما ستكون قاعدة البيانات نافذة معلوماثية لمصانع الألبان تمكنها من معرفة المتاح من الألبان في

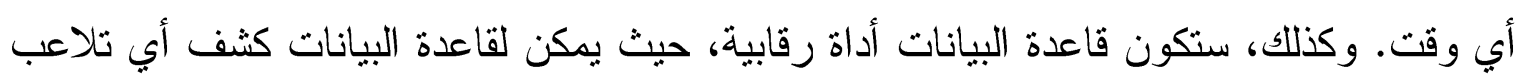

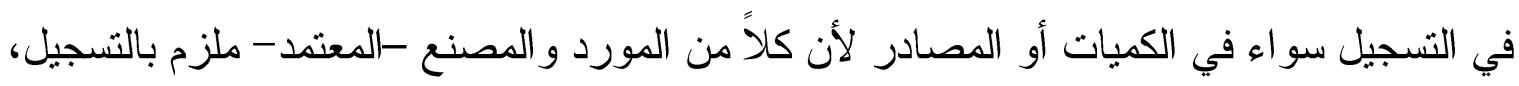
ومن السهولة لقاعدة البيانات رصد أي تضارب في البيانات.14 ويتوقع أن تنزايد جودة البيانات المسلة في قاعدة البيانات مع الاستمرار في جهود تطوير القطاع، ولكن لا جدال أن إنشاء قاعدة البيانات هو ضرورة لضبط الأداء وتحسينه.

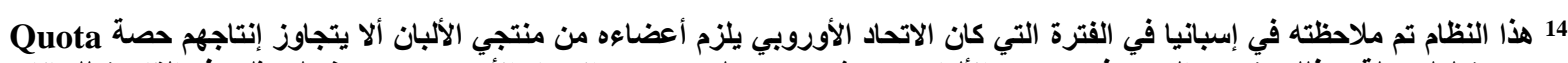

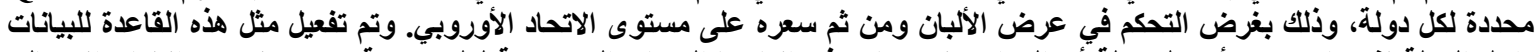

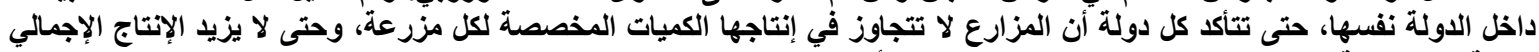
للاولة عن الحصة المقررة، وتتعرض لعقوبات من الاتحاد الأوروبي. 
العناصر الرئيسية للمشروع:

- تتسق الهيئة القومية لسلامة الغذاء مع وزارة التعاون الدولي، من أجل تحديد عدد من المشروعات العاملة في التمية الزراعية في مصر، والتي يمكنها أن تقوم بإنشاء قاعدة البيانات للايئة ضمن

الأنشطة التي تقوم بها.15

- تلزم الهيئة جميع مر اكز التجميع ومزارع إنتاج الألبان و المصانع المعتمدة منها أن تسجل مصادر جميع الكميات الواردة إليها، وكذلك وجهة الألبان المباعة وكمباتها. - كما تلزم الهيئة جميع مصانع الألبان المعتمدة منها بتسجيل مصادر وكميات الألبان الواردة إليها، ووجهة وكميات المنتجات المباعة.

مسئوليات التتفيذ: الهيئة القومية لسلامة الغذاء بالتتسيق مع وزارة التعاون الدولي، واللجنة العليا 3.4.1.5 مشروع تحفيز الطلب على منتجات الألبان التقليدية

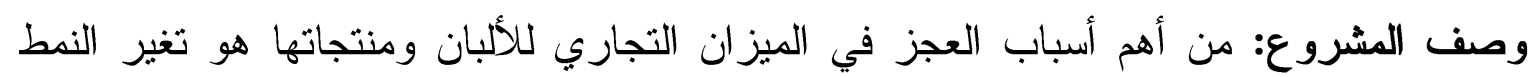
الاستهلاكي لثريحة كبيرة من المواطنين عزفت عن تتاول الجبن التقليدية المعتمدة على الألبان الطبيعية المنتجة محلياً متل القريش، و الجبن الدمياطي (الإسطنبولي و البراميلى)، و الجبن الراس (الجبن الرومي)، وكذلك في صعيد مصر ، لم تعد الجبن الفيومي، و الجبن المالاوى (نسبة إلى مركز

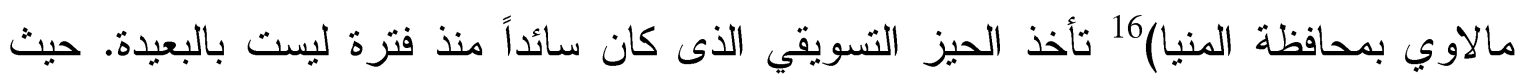
أصبحت بدائل الجبن الطبيعية Imitated cheese مهثلة في الجبن الطري نباتي الدهن (الفيتا والثلاجة)، والجبن المطبوخ (الجبن النستو) المعتمدة على الألبان المجففة والزيوت النباتية المستوردة، هي النمط الاستهلاكي الأكثر شيوعاً في السوق المصري. لذا، يهدف هذا المشروع إلى إقامة مهرجان سنوي للألبان المصرية في محافظة الإسكندرية على الى سيري غرار مهرجان التمور المصرية في واحة سيوة 17.

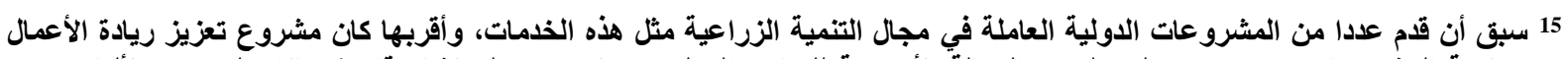

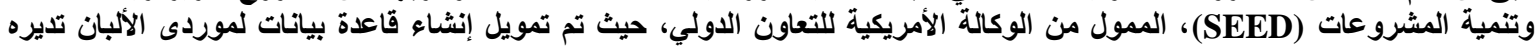

مؤسسة اقتصاد المعرفة. وسبق أن تعاون المشروع نفسه مع الهيئة القومية لتلامة الغذاء في عدد من الأنثطة التنريبية والتئية التوعوية.

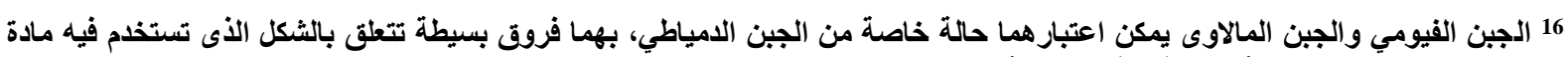
التجبن الإنزيمى "المنفحة"، وكذلك في الطريقة التي يتم بها التخلص من التهن الثرشي.

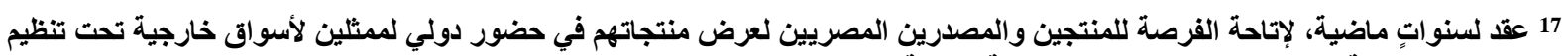

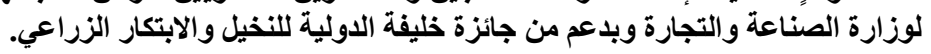


الندوات العلمية، معرض لمنتجات الألبان "التصديرية" من اللبن الخام، وكذلك مسابقة لأفضل مُنتج

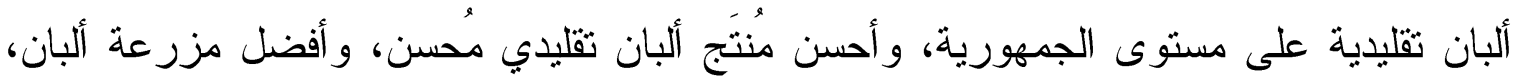
و أفضل مركز تجميع، وغيرها من المسابقات التي تخلق المنافسة بين العاملين في قطاع الألبان

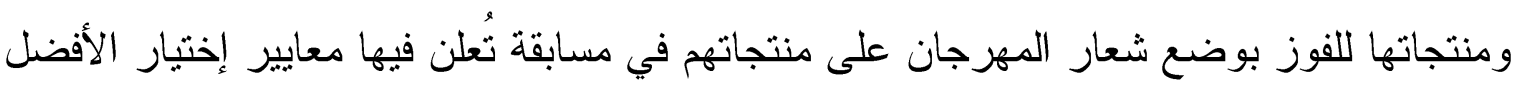
بشفافية (قاسم، 2018).

\section{العناصر الرئيسية للمشروع: - مانية}

- يتولى مجلس الصناعة للتكنولوجيا و الابتكار التابع لوزارة التجارة و الصناعة بالتتسيق مع محافظة

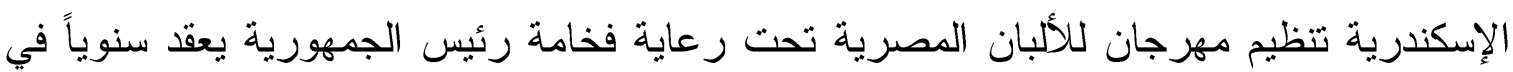
الإسكندرية لمدة 3 أيام. - تشكل لجنة عليا للمهرجان تثمل ممثلين لمجلس الصناعة للتكنولوجيا و الابتكار ، محافظة الإسكندرية،

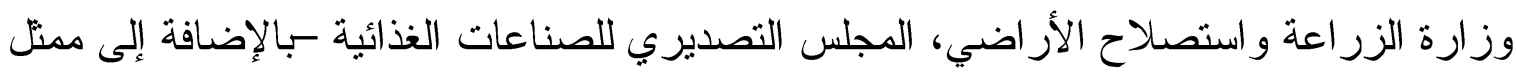
للمصدرين يرشحه المجلس-، جهاز تتمية المشروعات الصغيرة و المتوسطة، هيئة تتمية الصادرات، غرفة الصناعات الغذائية، منظمة الأغذية و الزراعة للأمم المتحدة، منظمة الأمم المتحدة للتنمية

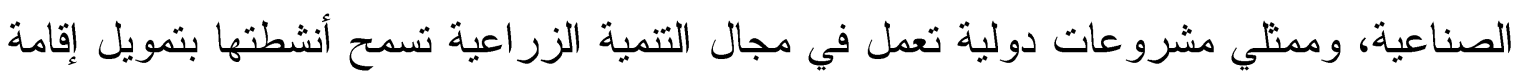

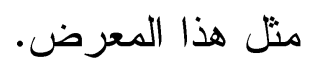
- يسند التنظيم إلى شركة تنظيم ذات خبرة في تنظيم المعارض تنولى التسويق للمهرجان تحت إثر اف اللجنة العليا للمهرجان. - يتم دعوة المصدرين للمشاركة في المعرض وعرض منتجاتهم من الألبان التقليدية في حضور مستوردين تتولى دعوتهم هيئة تتمية المعارض. - تضع اللجنة معايير اختيار أفضل مصنع لمنتجات الألبان التقليدية، و أحسن منتج ألبان تقليدي مُحسن،

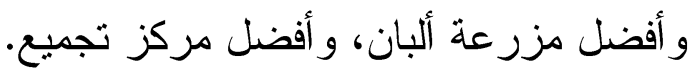
- تُعلن معايير الاشتر اك في المسابقة، وآليات التسجيل، وتقوم اللجنة بتشكيل فرق تقيبيم لزيارة من تقدم للمشاركة في المسابقة. - يتولى تمويل أنشطة المهرجان رعاة تختار هم اللجنة العليا للمهرجان. بالإضافة إلى مساهمة الجهات الأعضاء في اللجنة المنظمة. مسئوليات التتفيذ: مجلس الصناعة للتكنولوجيا والابتكار ومحافظة الإسكندرية بالتتسيق مع اللجنة العليا 
3.4.2 برنامج توطين الجبن الجاف والنصف جاف وأهم الصناعات المغذية لصناعة الألبان

$$
\text { ومنتجاتها }
$$

وصف البرنامج: من وجهة نظر الدراسة، أن توفر المادة الخام الأولية بالكميات و المواصفات التي تضمن تصنيع جيد وبتكلفة اقتصادية هو عامل أساس لتوطين سلاسل التوريد. ولذا، فإن هذا البرنة البرنامج

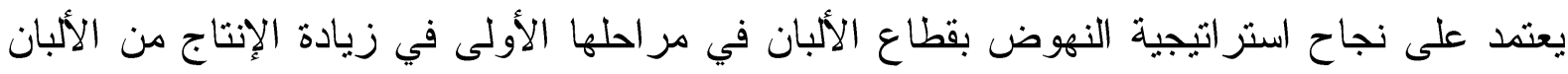

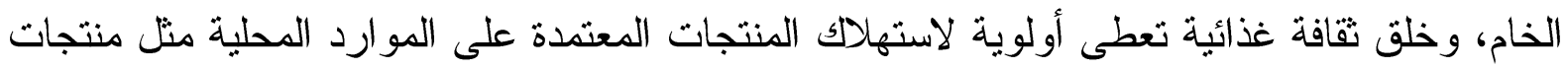

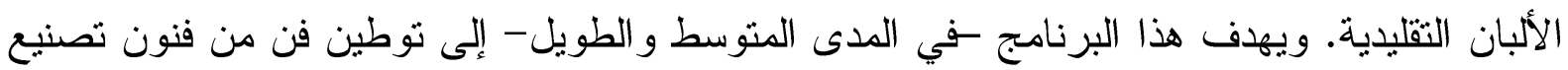

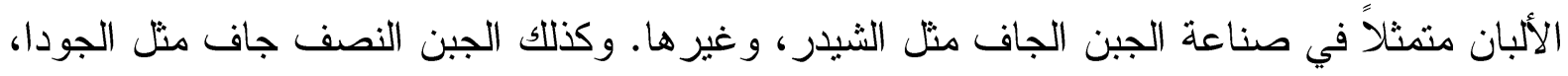

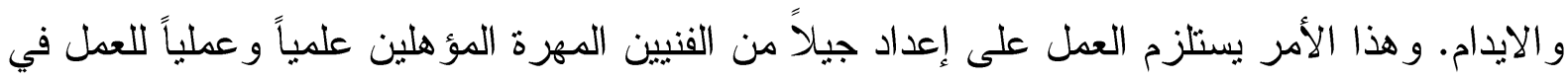
هذه الصناعة و غيرها من الصناعات المعتمدة على الألبان.

كما يهدف البرنامج أيضاً إلى توطين أهم الصناعات المغذية لصناعة الألبان، مثل بروتين الثرش،

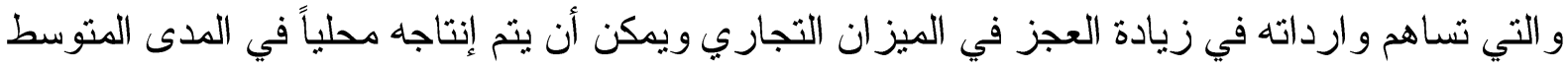

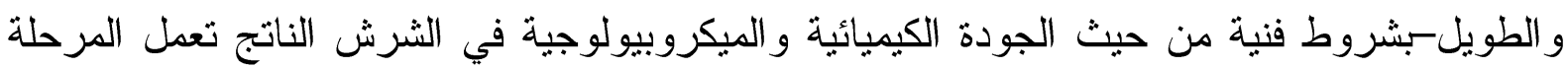

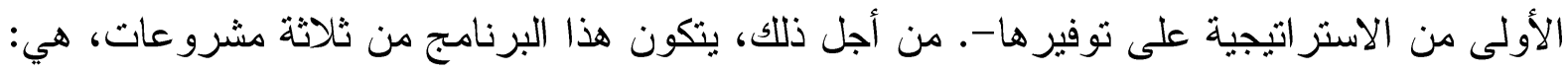

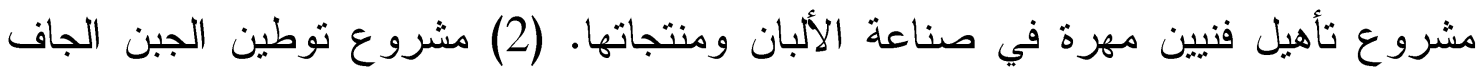
و النصف جاف. (3) مشروع نوطين الصناعات المعتمدة على شرش اللبن.

\subsubsection{1 مشروع تأهيل فنيين مهرة في صناعة الألبان ومنتجاتها} وصف المشروع: يهذف المشروع إلى تأهيل الفنيين سواء من الطلاب أو الخريجين من المدارس الفنية الفئية

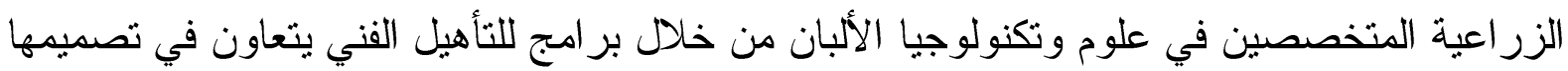

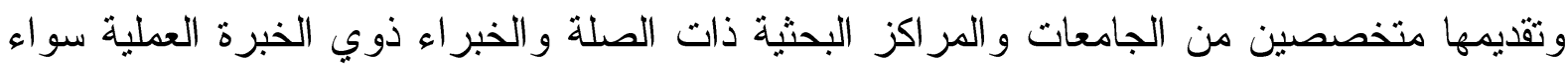
محليين أو دوليين.

\section{العناصر الأساسية للمشروع}

- - بالتسيق بين وزارة التزبية و التعليم و التعليم الفني ووزارة التعاون الدولي، يتم تحديد المشروعات الدولية العاملة في مجال التتمية الزر اعية التي تتضمن أنثطنها تقديم التدريب الفني لطلاب وخئ وخريجين

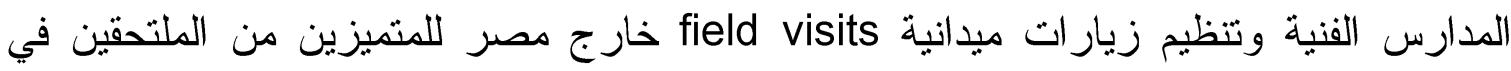
البرنامج في أحد البلدان الكبرى في تصنيع الجبن مثل فرنسا أو ألمانيا أو إيطاليا. 
- يتم إعداد منهج تدريبي "متقدم-عملي" من قبل أكاديميين وخبراء محليين أو دوليين تتعاقد معهم

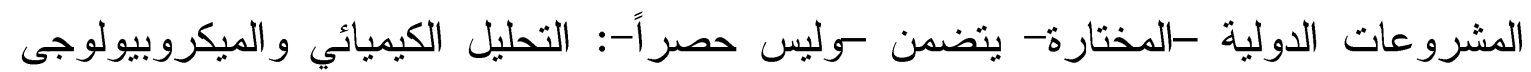

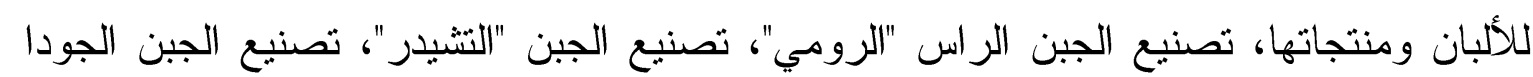

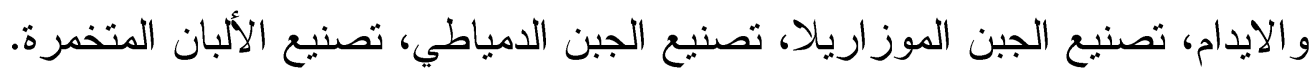

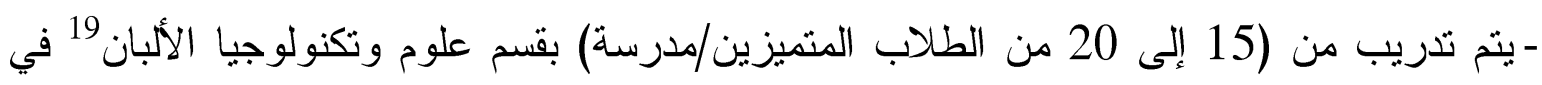

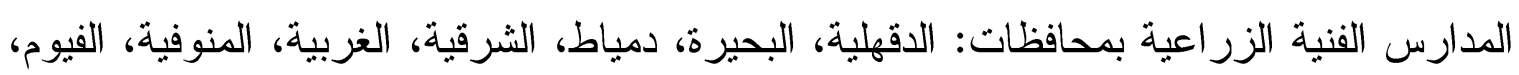
بنى سويف، المنيا على البرامج السابق ذكر ها.

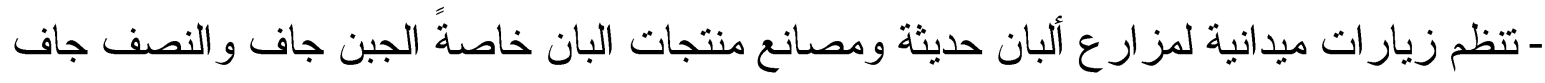
خارج مصر لعدد من المندربين المتميزين. ـ يشمل البرنامج تدريباً للددربين لعناصر مختارة من مدرسي التعليم الفني الزر اعي في المحافظات الدذكورة. مسئوليات التنفيذ: وزارة التربية والتعليم والتعليم الفني ووزارة النعاون الدولي بالتتسيق مع اللجنة العليا 3.4.2.2. مشروع توطين صناعة الجبن الجاف و النصف جاف

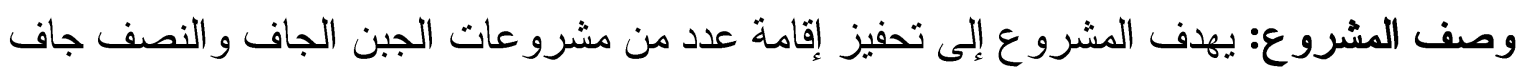

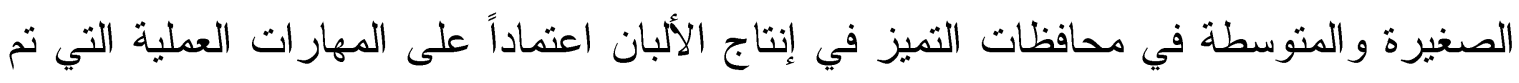
إكسابها لطلاب وخريجي المدارس الفنبة في محافظات الدقهلية، البحيرة، دمياط، الثرقية، الغربية،

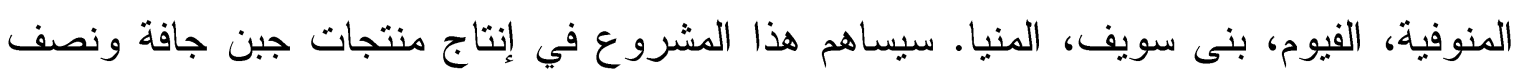

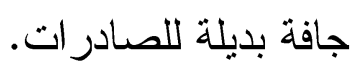

\section{العناصر الرئيسية للمشروع}

- بالتسيق بين الإدارة الصناعية بجهاز تتمية المشروعات الصغيرة و المتوسطة و اللجنة العليا يقوم الجهاز بإعداد -أو تحديث- دراسات تجارية Business plans لمشروعات صغيرة ومتوسطة ولئة

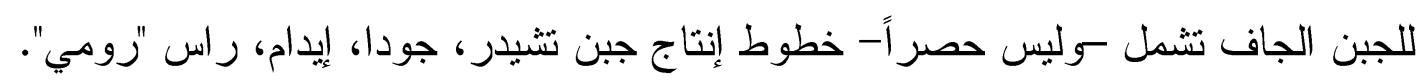
- تشمل الدراسات التجارية در اسة للسوق، وتحديد أهم القنوات التسويقية.

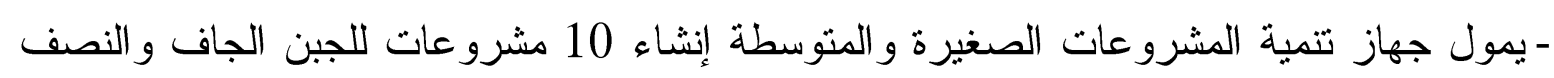

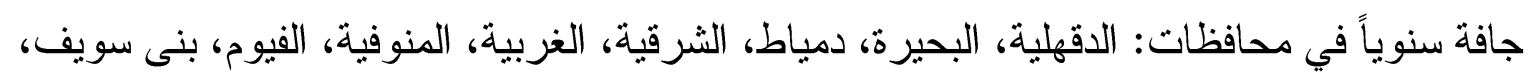
المنيا.

- تُططى أولوية لخريجي برنامج "تأهيل فنيين مهرة في صناعة الألبان ومنتجاتها" (4.4.2.1). 
مسئوليات التنفيذ: جهاز تتمية المشروعات الصغيرة و المتوسطة بالتتسيق مع اللجنة العليا وفقاً لبنود آلية

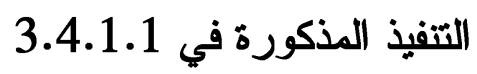

\subsubsection{3. مشروع توطين الصناعات المعتمدة على شرش اللبن}

وصف المشروع: يهدف هذا المشروع إلى الاستفادة من شرش اللبن سفي المدى المتوسط والطويل-

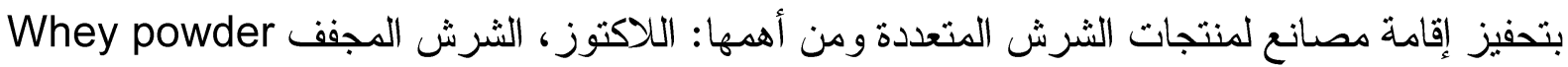
في حال تجفيف كامل الثرش، بروتين الشرش Whey protein في حال استخلاص البروتين فقط، وهو أغلى مشتقات الثرش و أكثرها استخداماً في صناعات منتجات الألبان ويتم استير اده بالكامل من

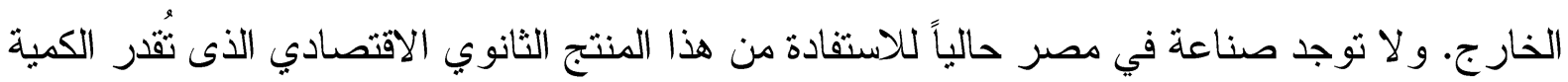

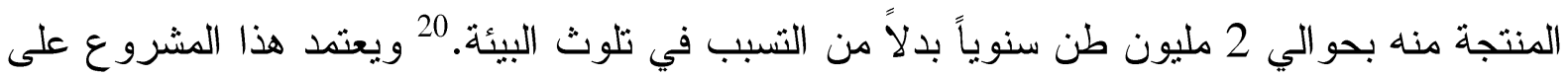

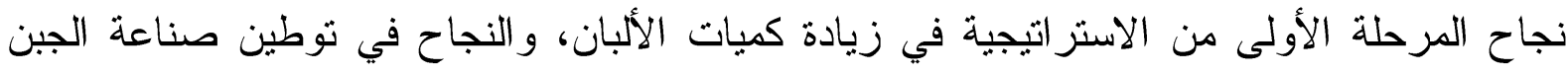

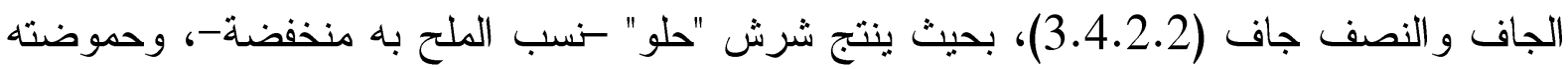
معتدلة، و العد الكلى به منخفض -بعد تحسين سلسلة التبريد-.

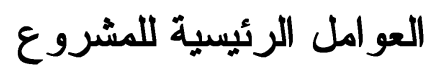

- تقوم هيئة الاستثمار و المناطق الحرة و هيئة التنمية الصناعية بالتسيق مع اللجنة العليا بطرح 5 فرص استثمارية لمطورين بالمناطق الصناعية: برج العرب، دمياط الجديدة، العاشر من رمضان،

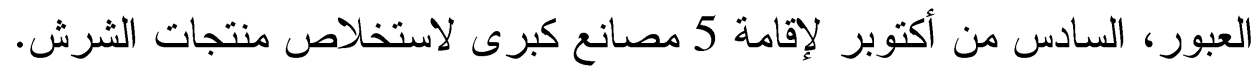

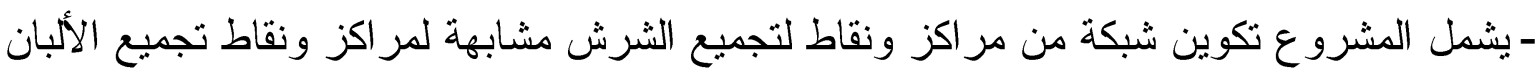

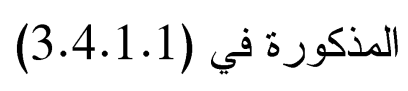

مسئوليات التنفيذ: هيئة الاستثمار والمناطق الحرة، وهيئة التنمية الصناعية بالتسيق مع اللجنة العليا الخلاصة

للألبان المصرية ومنتجاتها ميزة نسبية ظاهرة في أسواق التصدير، وخاصة في صناعة الجبن و الخثرة.

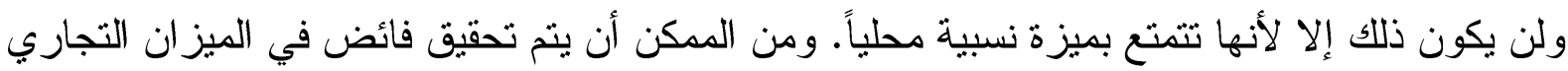

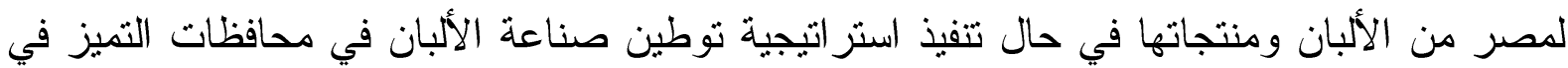
إنتاج الألبان.

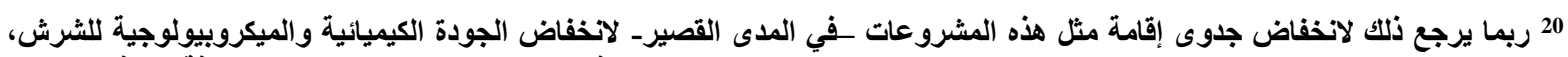

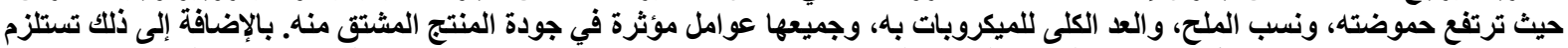

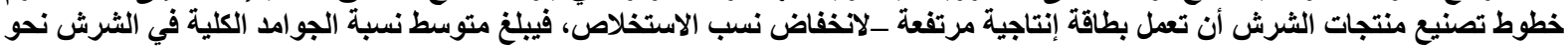

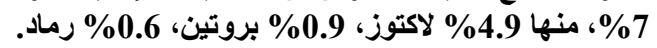




\section{المراجع}

\section{أولاً: مراجع باللغة العربية}

- أحمد جلال: نوطين الصناعة (2020). تم الاسترداد من مصر اليود (20 أغسطس، 2002). - - إير اهيم سليمان، محمد جابر (دكاتزة)، نظم التسويق الزراعي، دار الفكر العربي، - البو ابة: "الكفاءة الاقتصادية كضرورة لتوطين الصناعة بمصر" في ندوة متخصصة (2020). نم الاسترداد من البو ابة (20 أغسطس، 2020).

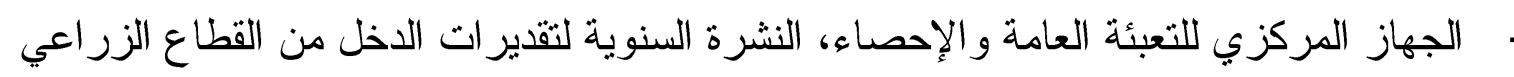
عام 2018/2017، مارس 2020. الثروق: رئيس الوزراء: توطين صناعة عربات القطار ات على أجندة أولوياتتا (2020). تم الاسترداد من: الشروق (20 أغسطس 2020) - الهيئة العامة للاستعلامات: الرئيس السيسي يوجه بالشروع في إطلاق الاستراتيجية القومية لتوطين صناعة المركبات و الصناعات المغذية لها (2020). تم الاسترداد من: الهيئة العامة للاستعلامات (20 أغسطس 2020). - - اليوم السابع. مستشار الرئيس: توطين صناعة البلازما في مصر قضية أمن قومي صحي

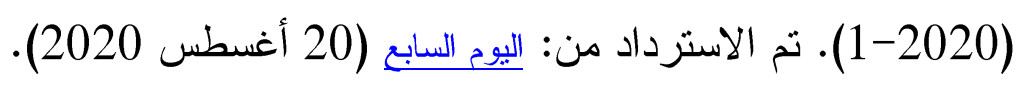

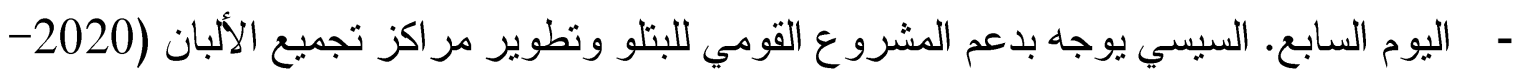

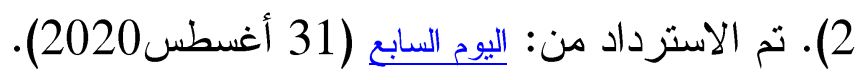
- رضا عبد الجليل (دكتور): عرض تقديمي خاص بأمثلة عن المنتجات الثانوية لصناعة الجنين

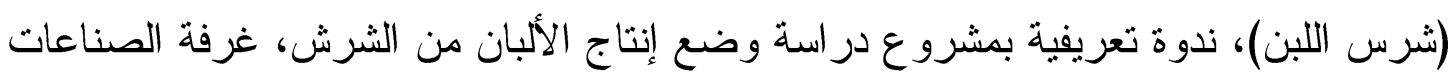

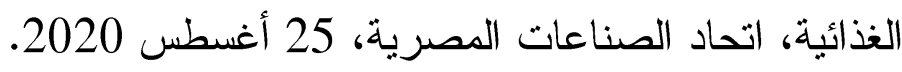
- على زين العابدين قاسم (دكتور): دراسة تقييم وتوصيف سلسلة قيمة الألبان، مشروع تعزيز

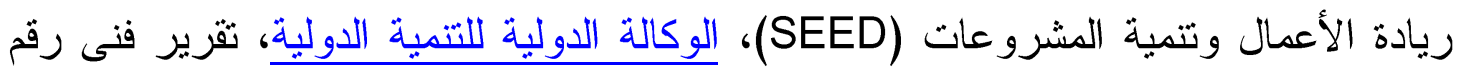
34، يونيو 2018. - مباشر مصر : رئيس الحكومة المصرية يتابع نطورات ملف "توطين الصناعة" (2020). تم

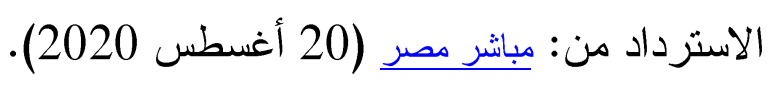
مصر اوي: الصناعة: سامسونج تخطط لضنخ استثمار ات جديدة في مصر بقيمة 84 مليون دو لار (2020). تم الاسترداد من: مصر اوي (20 أغسطس، 2020).

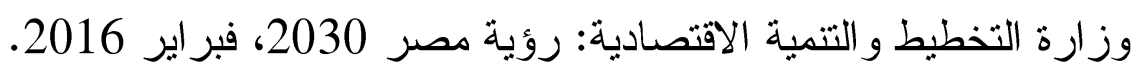


- وزارة الزراعة واستصلاح الأراضي، قطاع الثئون الاقتصادية، إحصاءات الإنتاج السمي

$$
\text { و الحشري و التصنيع الغذائي عام 2018، ديسمبر 2019). }
$$

- وزارة الزر اعة واستصلاح الأراضي، قطاع الثئون الاقتصادية، إحصاءات الثروة الحيوانية عام 2018، إصدار نوفمبر 2019.

\section{ثانيا: مراجع باللغة الأجنبية}

- Balassa, B. (1965), Trade Liberalization and Revealed Comparative Advantage, The Manchester School, 33, 99-123

- Cambridge English Dictionary. (2020, August 13). Localization. Retrieved from Cambridge English Dictionary: https://dictionary.cambridge.org/dictionary/english/localization

- Martin, A., \& Rickard, S. (2020). Supply Chain Localization Strategies for the Future: A study of Swedish AIE companies. Göteborg: Chalmers University of Technology.

- Ward, D. (2019, January). Water Requirements of Livestock. Retrieved August 31, 2020, from Ontario Ministry of Agricultural, Food and Rural Affairs: http://www.omafra.gov.on.ca/english/engineer/facts/07-023.htm\#1

- Weber, A. (1929). Alfred Weber's Theory of the Location of Industries . Chicago: University of Chicago Press.

- Zhong, T. (2020). Impact of state-led food localization on suburban districts' farmland use transformation: Greenhouse farming expansion in Nanjing city region, China. Landscape and Urban Planning.

ثالثاً: مواقع إلكترونية

https://www.aoad.org https://www.trademap.org خريطة التجارة -

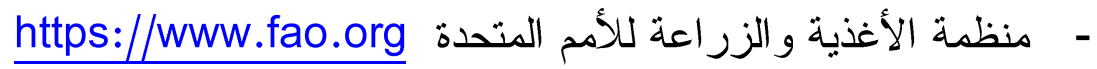

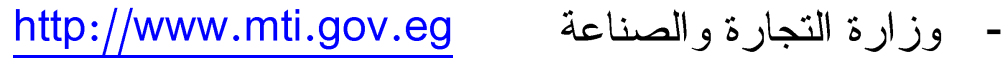




\section{شُكر وتمدير}

يتقام الباحث بالثكر والثقدير إلى الدكتور زهير الثندويلى مدير الإدارة الزراعية بجهاز تتمية المشروعات الصغيرة والمتوسطة، الدكتور أمجد القاضي مدير مركز تكنولوجيا الصناعات الغذائية و التصنيع الزر اعي، بوزارة الصناعة و التجارة، الأستاذ محمود طنطاوي مدير دعم التعليم والابتكار

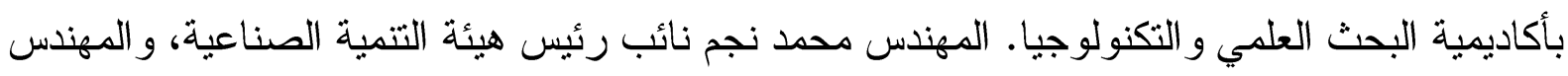
وليد البحراوي مدير الإدارة الغذائية بهيئة التتمية الصناعية. أ.د. عثمان عيطة أستاذ الألبان بكلية الزراعة جامعة عين شمس. م. حاتم كمال الإدارة الزراعية، جهاز تتمية المشروعات الصغيرة و المتوسطة، د. أحمد رشدي الباحث بمركز بحوث وتكنولوجيا الأغذية، وم. إبراهيم عبد الدايم مدير الجودة بشركة أراب ديرى "باندا"، م. محمد المصلى هدير الجودة بشركة لاكتليز، على المعلومات التي بلي أفادو ا بها الباحث، و الثي كان لها عظيم الأثر في إثر اء هذه الدراسة. 


$$
\begin{aligned}
& \text { (ملحق) جدول 1: أعداد الأبقار و الجاموس وعدد المذبوحات } \\
& \text { خلال الفترة من 2007-2016 }
\end{aligned}
$$

\begin{tabular}{|c|c|c|c|c|c|c|c|}
\hline \multirow{2}{*}{ أعدافي } & \multirow[b]{2}{*}{ عدد المذبوحات } & \multirow[b]{2}{*}{ إجمالي الأبقار والجاموس } & \multirow[b]{2}{*}{ الجاموس } & \multicolumn{3}{|c|}{ الأبقار } & \multirow[b]{2}{*}{ السنوات } \\
\hline & & & & إجمالي & أجنبي & 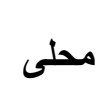 & \\
\hline 5932 & 3024 & 8684 & 3977 & 4707 & 159 & 4548 & 2007 \\
\hline 6049 & 2536 & 9176 & 4153 & 5023 & 165 & 4858 & 2008 \\
\hline 6070 & 2641 & 8364 & 3839 & 4525 & 130 & 4395 & 2009 \\
\hline 5944 & 2716 & 8547 & 3818 & 4729 & 146 & 4583 & 2010 \\
\hline 6525 & 2586 & 8763 & 3983 & 4780 & 143 & 4637 & 2011 \\
\hline 6096 & 2667 & 9111 & 4165 & 4946 & 148 & 4798 & 2012 \\
\hline 5968 & 2579 & 8660 & 3915 & 4745 & 148 & 4597 & 2013 \\
\hline 5848 & 2516 & 8711 & 3949 & 4762 & 145 & 4617 & 2014 \\
\hline 6649 & 2527 & 8585 & 3702 & 4883 & 198 & 4685 & 2015 \\
\hline 6219 & 2465 & 8956 & 3944 & 5012 & 260 & 4752 & 2016 \\
\hline 6130 & 2625.7 & 8755.7 & 3944.5 & 4811.2 & 164.2 & 4647 & المتوسط \\
\hline 5848 & 2465 & 8364 & 3702 & 4525 & 130 & 4395 & الحد الأدنى \\
\hline 6649 & 3024 & 9176 & 4165 & 5023 & 260 & 4858 & الأقصى الحد \\
\hline
\end{tabular}

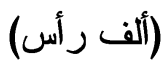

المصدر : منظمة الأغذية والزراعة للأمم المتحدة: قاعدة البيانات الإحصائية، أخر دخول في 30 أغطس 2020. 
(ملحق) جدول 1: كميات الإنتاج و الصادر ات و الو اردات و المتاح للاستهلالك من الألبان ومنتجاتها في مصر خلا الفترة (2000-2016)

\begin{tabular}{|c|c|c|c|c|c|}
\hline المتاح للاستهلاك & نسبة الاكتفاء الذاتي & كمية الواردات & كمية الصادرات & الإنتاج & العام \\
\hline 4796.66 & 76.43 & 1156.65 & 25.99 & 3666.00 & 2000 \\
\hline 4836.90 & 79.20 & 1033.35 & 27.45 & 3831.00 & 2001 \\
\hline 5144.25 & 79.39 & 1114.84 & 54.59 & 4084.00 & 2002 \\
\hline 6174.32 & 83.38 & 1078.16 & 51.84 & 5148.00 & 2003 \\
\hline 5090.81 & 86.29 & 754.52 & 56.71 & 4393.00 & 2004 \\
\hline 6500.61 & 87.67 & 952.41 & 150.80 & 5699.00 & 2005 \\
\hline 6041.18 & 93.67 & 524.41 & 142.23 & 5659.00 & 2006 \\
\hline 6236.91 & 92.51 & 572.92 & 106.01 & 5770.00 & 2007 \\
\hline 5884.23 & 101.87 & 858.25 & 968.02 & 5994.00 & 2008 \\
\hline 5279.68 & 109.36 & 676.35 & 1170.67 & 5774.00 & 2009 \\
\hline 4996.22 & 115.57 & 2014.86 & 2792.64 & 5774.00 & 2010 \\
\hline 6579.00 & 88.10 & 2290.00 & 1510.60 & 5799.00 & 2011 \\
\hline 5772.00 & 99.10 & 976.00 & 923.10 & 5719.00 & 2012 \\
\hline 5796.04 & 95.82 & 1355.31 & 1113.26 & 5554.00 & 2013 \\
\hline 5880.81 & 95.24 & 1243.41 & 963.60 & 5601.00 & 2014 \\
\hline 5949.70 & 94.10 & 1423.77 & 1072.55 & 5598.48 & 2015 \\
\hline 5666.00 & 90.00 & 1157.10 & 580.10 & 5089.00 & 2016 \\
\hline
\end{tabular}

المصدر : جمعت وحسبت من بيانات قاعدة البيانات الإحصائية لمنظمة الأغذية والزر اعة للأمم المتددة، أخر دخول: 30 أغسطس

(ملحق) جدول 2: تقدير معادلات الاتجاه العام لنطور كميات الإنتاج و الصادرات و الواردات و المتاح للاستهلاك من الألبان ومنتجاتها في مصر خلات الفاه الفترة (2000-2016)

\begin{tabular}{|c|c|c|c|c|}
\hline المتاح للاستهلاك & كمية الواردات & كمية الصادرات & الإنتاج & المتغير \\
\hline 0.085 & 0.059 & 0.323 & 0.402 & معامل التحديد المعدل \\
\hline 2.483 & 2.006 & 8.643 & 11.755 & قيمة (ف) المحسوبة \\
\hline 0.136 & 0.177 & 0.010 & 0.004 & مستوى معنوية (ف) \\
\hline 5346.88 & 875.89 & -25.29 & 4445.71 & قاطع المعادلة \\
\hline 250.7 & 209.0 & 284.8 & 273.1 & الخطَأ المعياري \\
\hline 0.000 & 0.000 & 0.930 & 0.000 & مستوى المعنوية \\
\hline 42.120 & 31.561 & 89.265 & 99.82 & معامل الانحدار \\
\hline 26.729 & 22.283 & 30.364 & 3.43 & الخطأ المعياري \\
\hline 0.136 & 0.177 & 0.010 & 0.004 & مستوى المعنوية \\
\hline 92.36 & 1126.58 & 695.63 & 5254.97 & المتوسط العام \\
\hline 76.43 & 524.41 & 25.99 & 3666.00 & الحد الأدنى \\
\hline 115.57 & 2290.00 & 2792.64 & 5994.00 & الحد الأقصىى \\
\hline $0.74 \%$ & $2.80 \%$ & $12.83 \%$ & $1.90 \%$ & متوسط معدل التغير \\
\hline
\end{tabular}

المصدر : جمعت وحسبت من بيانات قاعدة البيانات الإحصائية لمنظمة الأغذية و الزر اعة للأمم المتحدة، أخر دخول: 30 أغسطس 2020. 


\section{(ملحق) جدول 3: كمية وقيمة وأسعار الألبان المجفقة الموردة إلى مصر \\ خلال الفترة (2001-2019)}

الكمية بالطن، و القيمة بالألف دولار

\begin{tabular}{|c|c|c|c|c|c|c|c|c|c|}
\hline \multicolumn{3}{|c|}{ الإجمالي } & \multicolumn{3}{|c|}{040221} & \multicolumn{3}{|c|}{040210} & \multirow{2}{*}{ العام } \\
\hline القيمة * & سعر الطن & كمية & القيمة * & سعر الطن & كمية & القيمة * & سعر الطن & كمية & \\
\hline 47047 & $2,018.98$ & 23,671 & 8176 & $2,066.21$ & 3,957 & 38871 & $1,971.75$ & 19,714 & 2001 \\
\hline 26930 & $1,715.75$ & 18,870 & 4842 & $1,763.44$ & 3,217 & 22088 & $1,668.05$ & 15,653 & 2002 \\
\hline 30802 & $1,523.28$ & 28,163 & 7801 & $1,608.60$ & 6,229 & 23001 & $1,437.95$ & 21,934 & 2003 \\
\hline 39783 & $1,845.51$ & 23,453 & 9119 & $1,858.01$ & 5,458 & 30664 & $1,833.01$ & 17,995 & 2004 \\
\hline 57107 & $2,052.79$ & 28,291 & 23796 & $2,204.51$ & 10,117 & 33312 & $1,901.07$ & 18,174 & 2005 \\
\hline 43910 & $2,016.00$ & 22,384 & 17782 & $2,135.97$ & 8,053 & 26129 & $1,896.03$ & 14,331 & 2006 \\
\hline 86477 & $2,350.38$ & 30,893 & 31369 & $2,249.63$ & 12,807 & 55109 & $2,451.12$ & 18,086 & 2007 \\
\hline 270922 & $3,298.24$ & 53,511 & 107856 & $3,634.01$ & 16,875 & 163066 & $2,962.47$ & 36,636 & 2008 \\
\hline 301268 & $3,928.37$ & 38,136 & 86826 & $3,803.19$ & 12,403 & 214442 & $4,053.55$ & 25,733 & 2009 \\
\hline 190215 & $1,921.98$ & 86,576 & 28224 & $1,188.67$ & 41,274 & 161991 & $2,655.29$ & 45,302 & 2010 \\
\hline 266588 & $1,972.40$ & 133,156 & 89129 & $1,824.67$ & 55,313 & 177459 & $2,120.14$ & 77,843 & 2011 \\
\hline 517183 & $3,066.43$ & 103,444 & 147307 & $2,634.99$ & 43,837 & 369875 & $3,497.88$ & 59,607 & 2012 \\
\hline 694107 & $3,800.81$ & 96,863 & 230681 & $3,837.80$ & 32,361 & 463426 & $3,763.82$ & 64,502 & 2013 \\
\hline 843576 & $4,340.74$ & 95,708 & 310556 & $4,717.02$ & 28,839 & 533020 & $3,964.47$ & 66,869 & 2014 \\
\hline 365589 & $2,449.48$ & 127,123 & 162589 & $2,654.25$ & 47,685 & 203000 & $2,244.71$ & 79,438 & 2015 \\
\hline 271298 & $2,073.48$ & 132,824 & 123110 & $2,281.32$ & 48,876 & 148187 & $1,865.63$ & 83,948 & 2016 \\
\hline 224694 & $2,611.35$ & 78,696 & 86089 & $3,089.56$ & 18,635 & 138604 & $2,133.13$ & 60,061 & 2017 \\
\hline 277177 & $2,477.74$ & 108,837 & 145943 & $3,136.18$ & 30,659 & 131234 & $1,819.31$ & 78,178 & 2018 \\
\hline 360458 & $2,712.09$ & 113,687 & 138053 & $3,152.65$ & 28,699 & 222405 & $2,271.53$ & 84,988 & 2019 \\
\hline 258,691 & 2,536 & 70,752 & 92,592 & 2,623 & 23,963 & 166,099 & 2,448 & 46,789 & المتوسط \\
\hline 26,930 & 1,523 & 18,870 & 4,842 & 1,189 & 3,217 & 22,088 & 1,438 & 14,331 & الحد الأدنى \\
\hline 843,576 & 4,341 & 133,156 & 310,556 & 4,717 & 55,313 & 533,020 & 4,054 & 84,988 & الحد الأقصى \\
\hline
\end{tabular}

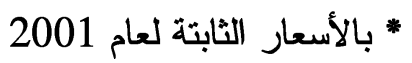

المصدر: جمعت وحسبت من بيانات خريطة التجارة (www.trademap.org)، أخر دخول: 30 أغسطس 2020. 
(ملحق) جدول 4: ثقدير معادلات الاتجاه العام لنطور كميات وقيم واردات الألبان ومنتجاتها إلى مصر خلال الفترة (2001-2019)

\begin{tabular}{|c|c|c|}
\hline قيمة اللبن المجفف & كمية اللبن المجفف & المتغير \\
\hline 0.360 & 0.721 & معامل التحديد المعدل \\
\hline 11.141 & 47.561 & قيمة (ف) المحسوبة \\
\hline 0.004 & 0.000 & مستوى مغنوية (ف) \\
\hline 28,310 & 12,014 & قاطع المعادلة \\
\hline 80,801 & 9,970 & الخطّأ المعياري \\
\hline 0.730 & 0.000 & مستوى المحنوية \\
\hline 25,598 & 6,526 & معامل الانحدار \\
\hline 7,669 & 946 & الخطأ المعياري \\
\hline 0.004 & 0.000 & مستوى المعنوية \\
\hline 258,691 & 70,752 & المتوسط العام \\
\hline 26,930 & 18,870 & الحد الأدنى \\
\hline 843,576 & 133,156 & الحد الأقصى \\
\hline $9.90 \%$ & $9.22 \%$ & متوسط معدل التغير السنوي \\
\hline
\end{tabular}

المصدر: جمعت وحسبت من بيانات خريطة التجارة Trade Map، أخر دخول: 31 أغسطس 2020. (ملحق) جدول 5: مقارنة قيمة الو اردات و الصادر ات و الميزان التجاري للنتجات الألبان عامي 2015، 2019

(ألف دو لار)

\begin{tabular}{|c|c|c|c|c|c|c|}
\hline \multicolumn{3}{|c|}{2015} & \multicolumn{3}{|c|}{2019} & \multirow{2}{*}{ لبند الجمركي } \\
\hline الميزان التجاري & الواردات & الصادرات & الميزان التجاري & الواردات & الصادرات & \\
\hline 11,325 & 800 & 12,125 & 26,426 & 745 & 27,171 & 0401 \\
\hline$(301,486)$ & 312,615 & 11,129 & $(265,511)$ & 285,785 & 20,274 & 0402 \\
\hline (499) & 533 & 34 & $(225)$ & 655 & 430 & 0403 \\
\hline$(67,949)$ & 68,324 & 375 & $(81,452)$ & 81,939 & 487 & 0404 \\
\hline$(224,925)$ & 226,816 & 1,891 & $(141,462)$ & 143,252 & 1,790 & 0405 \\
\hline 189,158 & 149,865 & 339,023 & 126,080 & 127,288 & 253,368 & 0406 \\
\hline$(394,376)$ & 758,953 & 364,577 & $(336,144)$ & 639,664 & 303,520 & الإجمالي \\
\hline
\end{tabular}

المصدر: خريطة التجارة. تم الاخول إليها أخر مرة في 22 أغسطس 2020.

(0401) اللبن و القشدة، غير المركزة أو بدون إضافة سكر أو أي مادة أخرى للتحلية. (0402) اللبن

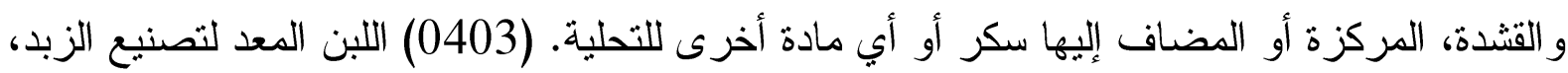

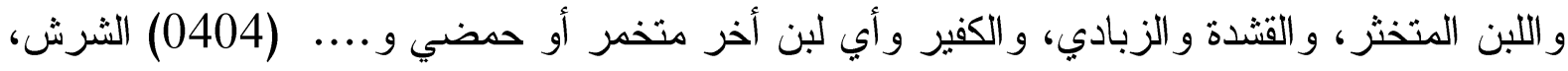

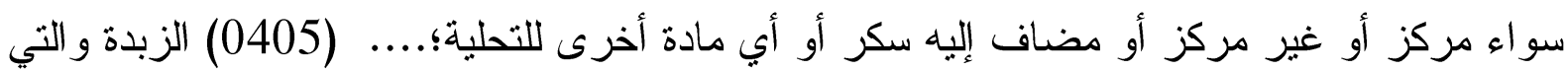
تتضمن الزبدة المجفة و السمن وغير ها من الدهون و الزيوت الأخرى المشتقة من اللبن؛.... (0406)

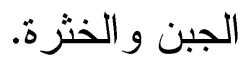


(ملحق) جدول 6: مؤشرات التجارة لأهم بنود صادرات الألبان ومنتجاتها المصرية عام 2019 (ألف دو لار)

\begin{tabular}{|c|c|c|c|c|c|c|c|c|c|}
\hline صي صناهيمة & التجاريزان & المُلتيمةت & 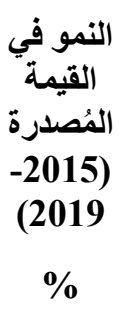 & 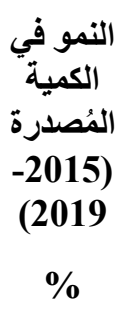 & العشادرة & 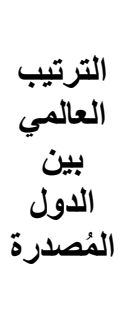 & المتوسطة & المستوردة & المُنتُج \\
\hline 45.66 & 114532 & 138594 & $-8 \%$ & $-13 \%$ & 5.2 & 6 & 1751 & 0.13 & 040630 \\
\hline $21.32 \%$ & 64295 & 64724 & $-7 \%$ & $-3 \%$ & 0.9 & 17 & 1379 & 0.12 & 040610 \\
\hline $15.21 \%$ & -46298 & 46174 & $12 \%$ & $21 \%$ & 0.2 & 35 & 1749 & 0.16 & 040690 \\
\hline $6.71 \%$ & 20357 & 20379 & 31 & 40 & 2.2 & 10 & 3113 & 0.34 & 040110 \\
\hline $6.39 \%$ & 18294 & 19382 & 23 & 53 & 5.1 & 7 & 2442 & 0.11 & 040229 \\
\hline
\end{tabular}

المصدر : جمعت وحسبت اعتماداً على بيانات خريطة التجارة، تم الذخول إليها أخر مرة في 23 أغسطس 2020. (040630) جبن مطبوخة، غير مبشور أو مسحوق. (040610) الجبن الطازج "الجبن غير الناضج أو غير المخمر"، بما في ذلك الجبن. جبن مصل اللبن و اللبن الر ائب. (040690) الجبن (باستثاء الجبن الطازج، بما في ذلك جبن مصل اللبن و اللبن الرائب والجبن المطبوخ والجبن ذات العروق الزرقاء و الجبن الأخرى المحتوية على عروق من إنتاج "بنسيليوم روكفورتي" و الجبن المبشور أو المسحوق). (040110) الحليب و القتشدة التي تحتوي على دهون بالوزن >= 1\%، غير مركزة و لا تحتوي على سكر مضاف. (040229) الحليب و القثدة في صورة صلبة، محتوى دهني بالوزن> 1.5\%، محلى. 
(ملحق) جدول 7: مؤشرات التجارة لأهم بنود الألبان ومنتجاتها المُوردة إلى مصر عام 2019

\begin{tabular}{|c|c|c|c|c|c|c|c|c|c|c|}
\hline والمي قيمة & التجاري & المستنجات & $\begin{array}{c}\text { النموة } \\
\text { القيتّردة } \\
\text {-2015) } \\
\text { (2019 } \\
\text { \% } \\
\end{array}$ & $\begin{array}{c}\text { النموية } \\
\text { المستوردة } \\
\text { الكمئو } \\
\text { (2015) } \\
\text { \% } \\
\end{array}$ & المشاركة & العالمي بين & مالمع دمسافة & تركيز & الجمريفة & المُنتج \\
\hline 30.18 & 193047 & 193053 & $1 \%$ & $1 \%$ & 2.6 & 12 & 4469 & 0.14 & 0 & 040210 \\
\hline 14.46 & -46298 & 92472 & $-5 \%$ & $-7 \%$ & 0.5 & 33 & 6693 & 0.24 & 1.9 & 040690 \\
\hline 14.14 & -90101 & 90478 & $-8 \%$ & $-14 \%$ & 0.9 & 24 & 13775 & 0.54 & 4.5 & 040221 \\
\hline 14.04 & -89409 & 89807 & $-10 \%$ & $-18 \%$ & 1.3 & 20 & 8898 & 0.26 & 1.9 & 040510 \\
\hline 9.66 & -61448 & 61797 & $4 \%$ & $-5 \%$ & 5.40 & 4 & 10550 & 0.25 & 2.6 & 040490 \\
\hline 8.16 & -50977 & 52191 & $-5 \%$ & $-18 \%$ & 2.5 & 14 & 13845 & 0.64 & 1.9 & 040590 \\
\hline
\end{tabular}

الصدرر: جمعت وحسبت اعتماداً على بيانات خريطة التجارة، تم الذخول إليها أخر مرة في 23 أغسطس 2020. (040210) الحليب و القتشدة في صورة صلبة ، محتوى دهني بالوزن >= 1.5٪. (040690) الجبن

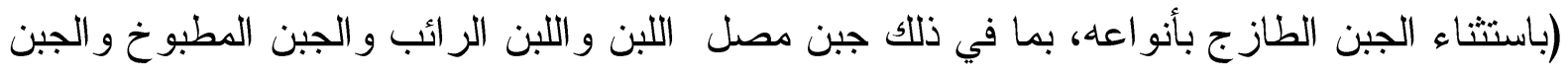
ذات العروق الزرقاء والجبن الأخرى المحتوية على عروق من إنتاج "بنسيليوم روكفورني" و الجبن التبن

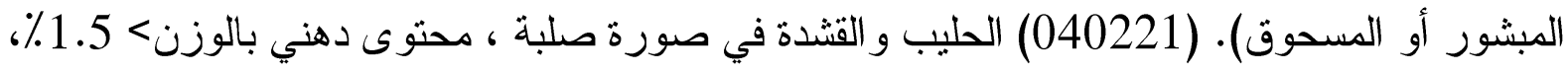

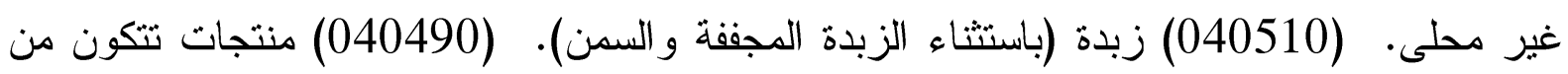

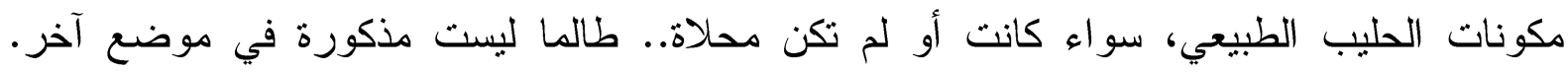

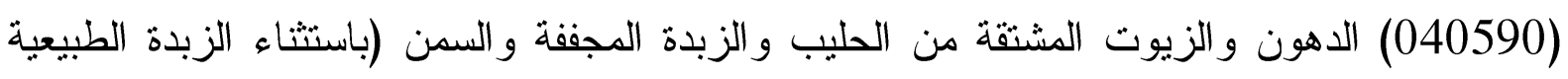
و الزبدة المعاد تجميعها وزبدة مصل اللبن). 